NBER WORKING PAPER SERIES

CULTURE, POLICIES AND LABOR MARKET OUTCOMES

Francesco Giavazzi

Fabio Schiantarelli

Michel Serafinelli

Working Paper 15417

http://www.nber.org/papers/w15417

\author{
NATIONAL BUREAU OF ECONOMIC RESEARCH \\ 1050 Massachusetts Avenue \\ Cambridge, MA 02138 \\ October 2009
}

We thank Paola Giuliano for very helpful discussions on the issues at stake and on the data, Daron Acemoglu and participants in the MIT macro lunch for very useful comments and suggestions. The views expressed herein are those of the author(s) and do not necessarily reflect the views of the National Bureau of Economic Research.

NBER working papers are circulated for discussion and comment purposes. They have not been peerreviewed or been subject to the review by the NBER Board of Directors that accompanies official NBER publications.

(C) 2009 by Francesco Giavazzi, Fabio Schiantarelli, and Michel Serafinelli. All rights reserved. Short sections of text, not to exceed two paragraphs, may be quoted without explicit permission provided that full credit, including (C) notice, is given to the source. 
Culture, Policies and Labor Market Outcomes

Francesco Giavazzi, Fabio Schiantarelli, and Michel Serafinelli

NBER Working Paper No. 15417

October 2009

JEL No. J16,J22,J23,Z1

\begin{abstract}
$\underline{\text { ABSTRACT }}$
We study whether cultural attitudes towards gender, the young, and leisure are significant determinants of the evolution over time of the employment rates of women and of the young, and of hours worked in OECD countries. Beyond controlling for a larger menu of policies, institutions and structural characteristics of the economy than has been done so far, our analysis improves upon existing studies of the role of "culture" for labor market outcomes by dealing explicitly with the endogeneity of attitudes, policies and institutions, and by allowing for the persistent nature of labor market outcomes. When we do all this we find that culture still matters for women employment rates and for hours worked. However, policies and other institutional or structural characteristics are also important. Attitudes towards youth independence, however, do not appear to be important in explaining the employment rate of the young. In the case of women employment rates, the policy variable that is significant along with attitudes, is the OECD index of employment protection legislation. For hours worked the policy variables that play a role, along with attitudes, are the tax wedge and unemployment benefits. The quantitative impact of these policy variables is such that changes in policies have at least the potential to undo the effect of variations in cultural traits on labor market outcomes.
\end{abstract}

Francesco Giavazzi

Department of Economics

Bocconi University and I.G.I.E.R

room 5-D1-07

Via. G. Rontgen 1

20136, Milan Italy

and NBER

francesco.giavazzi@unibocconi.it

Fabio Schiantarelli

Department of Economics

Boston College

Chestnut Hill, MA 02467

and IZA

schianta@bc.edu
Michel Serafinelli

Department of Economics

University of California, Berkeley

508-1 Evans Hall \# 3880

Berkeley, CA 94720-3880

serafine@econ.berkeley.edu 


\section{Introduction and motivation}

A number of labor market outcomes - the employment rate of women and of the young, the yearly hours worked by those who have a job - differ substantially across the OECD. In the period 19992002, for instance, the employment rate of those in the age bracket 16 to 25 was on average 41 per cent in Mediterranean countries, 43 percent in Continental Europe, and 58 per cent in AngloSaxon countries. In the same years the employment rate of women was 59 percent in Mediterranean countries and 80 percent in Nordic countries. These variables have also evolved differently within each group of countries over time: for instance, between the early 1980's and the beginning of this decade the employment rate of women has remained virtually constant in the Nordic countries, while it has increased by almost 20 percentage points in Continental Europe and in the AngloSaxon countries, and by 6 points in Japan. Average hours of work tend to decrease in the 80's, although at a different pace in each group of countries. In the 90's the rate of decrease tends to be smaller in Continental countries, and near to zero in Mediterranean and Nordic countries.

It has been claimed that attitudes towards gender and the young, what is sometimes referred to as a country's "culture", are important determinants of the cross-country and time series differences in the employment rates of various demographic groups.(see for instance Algan and Cahuc (2007) and Fortin (2005)). In related work, Alesina, Glaeser and Sacerdote (2005) have asked whether culture could explain the observed difference in hours worked between Europe and the United States, and Fortin (2008) has studied the effect of culture on an individual's decision to join the labor market in the United States.

However, the evidence on the role of "culture" on a country's labor market outcomes has so far been inconclusive, mainly for three reasons. First, as noted by Alesina, Glaeser and Sacerdote (2005), these papers often fail to allow for other factors that may determine labor market outcomes, in particular the differences across countries and the evolution within a country of economic structure (for instance the share of the services sector) and of labor market policies and institutions. Second, these analyses rarely recognize that the variables used to capture a country's "culture" are typically endogenous: attitudes towards leisure and work, for instance, are likely to be affected by a person's own labor market experience and by the experience of those around her. Finally, these papers seldom allow for the fact that employment rates and hours of work evolve gradually over time.

Our aim is to investigate whether culture plays a statistically and economically significant role when one tries to take care of the endogeneity of workers' attitudes, to allow for the persistent nature of labor market outcomes, and to control for a large menu of policies and institutions, recognizingas is the case of attitudes - that some of these variables are also likely to be endogenous.

The investigation of the effects of workers' attitudes on labor market outcomes is part of a more general research program aimed at assessing the effect of culture on economic phenomena. The endogeneity of cultural traits is one of the central issues in this literature and various authors have tackled it different ways. Alesina and Giuliano (2007) use a variable based on the grammatical rule of pronoun drop as an instrument for a particular cultural trait: family ties. Guiso, Sapienza and 
Zingales (2006) use the percentage of adherents to various religious denominations as an instrument for thrift, a cultural trait supposed to affect aggregate saving. Licht, Goldschmidt and Schwartz (2007) and Tabellini (2008b) investigate the role of culture in determining the quality of institutions, and also use a linguistic variable as an instrument for culture. ${ }^{1}$ These papers are mostly cross sectional in nature. Even if repeated observations over time are available, country-fixed effects are typically not introduced because the instruments have little or no time variation. The exception is Tabellini (2008a) who instruments cultural traits - such as trust, obedience and respect - with past literacy rates and past institutions, and runs a cross sectional regression with regional data. This allows him to introduce country-specific effects, but obviously no region effects.

In their excellent survey of this literature Guiso, Sapienza and Zingales (2006) define culture as "those customary beliefs and values that ethnic, religious and social groups transmit fairly unchanged from generation to generation". This definition highlights the difficulties at identifying a country-specific effect of "culture". If culture is a time-invariant characteristic of a country it is very difficult to recover its causal influence on economic outcomes separately from the effect of other country-specific constant characteristics. ${ }^{2}$ This paper exploits the variation within countries as well as across countries of cultural attitudes, policies and institutions. The use of panel data information allows us, potentially, to assess the effect of the time varying component of culture, policies and institutions in determining a country's labor market outcomes, controlling for all time invariant country characteristics. We are unable, of course, to determine the extent to which crosscountry differences in labor market outcomes-in hours worked for instance - reflect time-invariant cultural traits, or time-invariant policies and institutions, because they will all be absorbed by the country fixed effects.

This approach is obviously informative only to the extent that attitudes, in addition to policies and institutions, have a significant time-varying component that differs across countries. This is the case, for instance, with the set of attitudes towards the role of women in the family and in the workplace - a potentially important cultural determinant of women employment outcomes: over the last quarter century, these particular attitudes have changed substantially and in a way that varies from one country to another. The same is true for attitudes towards desirable characteristics of the young, such as independence, and towards the value of leisure.

As in previous studies, we use the World Value Survey (WVS) to obtain a measure of attitudes towards women's work and towards youth independence, and assess their effect on the employment rate of women and the young, respectively. We also analyze the importance of attitudes towards holidays for average hours worked, a topic not investigated so far in the literature. Time varying measures for such attitudes are available at (approximately) equally spaced intervals of ten years for a set of OECD countries, from the beginning of the eighties to the beginning of the twenty first

\footnotetext{
${ }^{1}$ Brugger, Lalive and Zweimuller (2009) use a regression discontinuity design across language barriers in Switzerland to investigate the effect of culture on unemployment.

${ }^{2}$ In a cross sectional context, the basic problem resides in the questionable assumption of orthogonality between the culture variable (or the instruments used for it) and the error term in the equation of interest, since one cannot control for time invariant unobservables.
} 
century. ${ }^{3}$

As we already mentioned, a country's attitudes cannot be assumed to be exogenous. Attitudes towards women, or the young, or towards leisure are likely to be affected by present and past individual and aggregate labor market outcomes (in addition to policies and institutions). We thus need to use (time varying) instruments which are correlated with such attitudes but are uncorrelated with contemporaneous innovations in labor market outcomes - although they may reflect past innovations. In the dynamic panel estimation framework proposed by Arellano and Bond (1992) and Blundell and Bond (1998) these instruments can then be treated as predetermined variables. The GMM framework also allows us to account for the fact that labor market outcomes tend to have a degree of persistence over time, thus requiring the estimation of dynamic models for employment or hours.

One of the instruments we use is the percentage of people who believe in God, interacted with a country's historically prevalent religious affiliation (Catholic, Protestant, etc.). Another instrument reflects the degree of trust in others. Our identifying assumption is that the evolution over time of these instruments is correlated with the evolution over time of those attitudes that are more directly relevant for the labor market: attitudes toward gender roles, youth independence and importance of holidays. But, contrary to those attitudes, the variables we use as instruments (i) are not (contemporaneously) affected by labor market outcomes and (ii) affect outcomes only through such attitudes, once we control for other time varying policies, institutions and structural variables. ${ }^{4}$

We then extend our set of instruments to include the attitudes towards women and towards sex and trust of second or higher generation American immigrants from different countries at different point in times. The evolution over time of the attitudes of American immigrants is correlated with that of attitudes in the country of origin, but can be assumed to be exogenous because they respond to institutional and economic shocks in the U.S. but are unlikely to be correlated, under certain assumptions, with economic shocks in the country of origin ${ }^{5}$.

Our results thus improve upon previous findings, in particular on the seminal contributions of Algan and Cahuc (2007) and Fortin (2005) in three respects. Because those papers: (i) do not address the problem of endogeneity, (ii) rely on a static specification of labor market outcomes, and (iii) control for a much more limited menu of policies, institutions and structural variables.

We find that, even after instrumenting, controlling for the role of time-varying structure, policies

\footnotetext{
${ }^{3}$ They are also available for the mid 1990's, but we have decided to rely on the lower frequency variation in order to give more time to attitude to evolve and because the survey in the mid 1990's is available only for a subset of countries.

${ }^{4}$ Fortin (2008) uses individual attitudes towards sex and politics as an instrument for family attitudes in an equation that explains a woman's participation decision in the U.S..

${ }^{5}$ The correlation between the behavior of immigrants and that of residents in the country of origin has been noted and exploited by several authors. For instance, Giuliano (2007) documents and studies the similarity in the living arrangements of children of immigrants with those in the country of origin. Fernandez (2007) shows that women participation rates are related to the aggregate participation rate in the country of origin. Algan and Cahuc (2008) use the attitudes of American immigrants towards trust as an instrument to study the effect of trust on the growth rate of a country's per capita income in the long run (between 1935 and 2000).
} 
and institutions and for the persistence of participation and hours worked, culture still matters for two out of the three outcomes under study. Attitudes towards women's role in the family and attitudes towards leisure are statistically and economically important determinants of the employment rate of women and of average hours worked, respectively. However, policies and other institutional or structural characteristics of the labor market also matter, even when we recognize that policies and institutions may be endogenous because they may reflect changing economic conditions and cultural values. Attitudes towards youth independence, however, do not appear to be important in explaining the employment rate of the young. In the case of women employment rates, the policy variable that is significant along with attitudes, is the OECD index of employment protection legislation. For hours worked the policy variables that play a role, along with attitudes, is the tax wedge and benefits. The quantitative impact of these policy variables is such that changes in policies have at least the potential to undo the effect of variations in cultural traits on labor market outcomes.

The paper is organized as follows. In Section 2 we describe how the WVS data can be used to measure attitudes in OECD countries. In Section 3 we describe the econometric problem one faces when trying to assess a causal effect of attitudes on labor market outcomes. We then describe two IV estimation strategies based, respectively, on the evolution of deeper attitudes and on the changes in attitudes of immigrants to the United States from various countries. In Section 4 we report the Within Estimates (which do not address the issue of endogeneity, nor the persistence of outcomes) to provide a baseline and a comparison with previous results. Section 5 and 6 contain a discussion of the choice of instruments and of the GMM estimates of dynamic models for employment and hours. Section 7 concludes.

\section{What do we mean by culture and how do we measure it?}

The World value Survey (WVS) - the main source of our data-includes a number of questions whose answers can be used to measure beliefs and values that are likely to be relevant for the aggregate employment rate of women and of the young, and for average hours of work. Such beliefs evolve over time, although they are likely to contain a country specific time invariant component.

The answers to a first set of questions capture a set of attitudes that, arguably, are of a direct relevance for labor market outcomes and will be used as explanatory variables in the employment or hours equation. One example is "Do you think that a woman has to have children in order to be fulfilled or is this not necessary?": this is the question whose answers we use to measure attitudes that could affect women employment rates. We also use the answers to the question "Do you agree or disagree with the following statement? When jobs are scarce, men should have more rights to a job than women", but more sparingly, since it is available for a shorter period of time. When using these answers one must be aware that high employment rates for women are likely to be both a cause and an effect of attitudes towards what is necessary for a woman's fulfillment. Moreover, the answer to such a question could be affected by policy - for instance by rasing the level of education 
of women - or by economic structure, for instance by changes in the share of the service sector in total employment - which presumably raises the number of jobs available for women. Another example is the question we use to measure attitudes that could affect hours worked: "Here are some more aspects of a job that people say are important. Please look at them and tell me which ones you personally think are important in a job. Generous holidays", where the answer might be affected by a worker's probability of finding (and/or maintaining) a job - if he asks for too frequent holidays - and thus by the cyclical state of the labor market, or by the strength of unions. ${ }^{6}$ The same is true for question we use to measure attitudes that could affect the employment rate of the young: "Here is a list of qualities that children can be encouraged to learn at home. Which if any do you consider to be especially important? Independence". The answer to this questions might be affected by fluctuations in the youth employment rate. We use the three questions we have just reported to identify the (time varying) role of attitudes on the three labor market outcomes we are interested in: the employment rate of women, that of the young, and the yearly hours worked by those who have a job.

Since we are concerned by the possible correlation of our measures of attitudes with current labor market conditions, as well as with policies and institutions, we need to find instruments to identify their effects on employment and hours. As mentioned in the Introduction, we use two sets of instruments. First, the answers to a set of questions in the WVS that reflect deeper attitudes, i.e. features of a society's beliefs and values that change over time, but do so only slowlyand are thus unlikely to be affected by current labor market conditions - yet are likely to contain information about the evolution over time of attitudes towards gender, youth and leisure. After some experimentation, the main variable we use are answers to the question: "Which, if any, of the following do you believe in? God". This religious attitude variable is interacted with a country's prevalent historical religious affiliation (Catholic, Protestant, and other (Japan)) We have also experimented with answers to the question "Apart from weddings, funerals and christenings, about how often do you attend religious services these days?". We will point out below the similarities and differences with the results obtained using the belief in God as an instrument.

We also use the answers to the question: "Generally speaking, would you say that most people can be trusted or that you can't be too careful in dealing with people?" (one possible answer being "Most people can be trusted", the others "Can't be too careful" and "Don't know"). The basic idea, as we shall discuss in Section 5, is that these deeper attitudes are likely to be correlated with attitudes towards women, the young and leisure that we use as explanatory variables, but they are not likely to affect labor market outcomes directly. Moreover, while outcomes and current policies can affect these deeper attitudes, they are assumed to do so only with a lag.

Second, we use as instruments the attitudes of second or higher generation immigrants to the United States, classified by country of origin, obtained from the U.S. General Social Survey (GSS). The idea here is that the evolution over time of the attitudes of each immigrant group is informative

\footnotetext{
${ }^{6}$ See Aghion, Algan and Cahuc (2008) for a theoretical and empirical investigation of the relationships between labour market institutions and policies and beliefs about cooperation in the labor market.
} 
about changes of attitudes in the country of origin, yet they are much less likely to be affected by shocks to labor market outcomes there. To capture the attitudes of US second (or third) generation immigrants towards women work we use answers to the question "Do you approve or disapprove of a married woman earning money in business or industry if she has a husband capable of supporting her?" We also explore as an instruments their attitude towards trust, measured in the same way as for the country of residence, and towards premarital sex. In this latter case we have used the answers to the question "There's been a lot of discussion about the way morals and attitudes about sex are changing in this country. If a man and woman have sex relations before marriage, do you think it is always wrong, almost always wrong, only sometimes, or not wrong at all? ". We will discuss in greater length our choice of instruments in Section 3 and 5 below and report the GMM estimates in Section 6.

Let us return now to the choice of explanatory variables. Since our dependent variables are aggregate labor market outcomes, the explanatory variable we are interested in are a country's average attitudes. For instance, when we study women's participation we are interested in gender attitudes of both women and men: the first since it a woman's decision whether or not to look for a job; the second, because hiring decisions could be made by men. Average attitudes however have a problem: they could move over time because the composition of the population (and thus of the sample in WVS) changes over time, not because the role of specific national features changes. For instance, the share of highly educated people in the sample could change. We could correct for this introducing such composition variables directly in the regression for aggregate outcomes, but this would consume too many degrees of freedom.

The alternative, following Algan and Cahuc (2007), and this is the strategy we have chosen, is to estimate a probit model for each question for each wave controlling for the main individual characteristics and including country-effects which capture the role of specific national features (see Table 1 for probit estimates for the wave 1999-2004). ${ }^{7}$ We control for age and age squared, for the level of education, the marital status, the number of children, the family income (coded by the surveys between low, middle and high income) and for the employment status. The inclusion of the employment status should minimize the risk that answers to the attitudinal questions may be a pure reflection of one's employment experience. We also include the respondent's political views (coded by the surveys between left, center and right) and their religious views by distinguishing the following main categories: Catholic, Protestant, Buddhist, Muslim, Jews, other religions and with no religion affiliation. The variables we use to measure cultural attitudes are thus the estimated wave specific country effects in the probit regressions for gender attitudes, for attitudes towards youth independence, and towards the importance of holidays. ${ }^{8}$ (We will follow a similar procedure

\footnotetext{
${ }^{7} \mathrm{~A}$ closely related alternative is to interact the country dummies with wave dummies, but to impose the restriction that the coefficients of the individual characteristics variables are constant through time.

${ }^{8}$ Actually Algan and Cahuc (2006a) use as regressor in the outcome equations the marginal effects of the country/wave variables. We do not follow this strategy because the average value of the individual variables affects the point at which the cumulative density function is evaluated to obtain the marginal effects. This may reintroduce composition effects that one intended to eliminate estimating a probit for each wave and recovering the wave specific country effects.
} 
to identify a country's average attitudes when we use instruments based on deeper attitudes of country of residence and US immigrants' attitudes. ${ }^{9}$ ). Using the within country variation of the country/wave effects one can hope to identify the effects on labor market outcomes of the time varying components of attitudes, controlling for those of components that remain unchanged over time and which cannot be separated form other country-specific and time-invariant components of institutions and policies that are captured by the country fixed effects.

We use data for those OECD countries in the WVS for which data are available at (approximately) equally spaced intervals of ten years (around 1980, 1990 and 2000) and we estimate the probit for the sample of working age population between 16 and 64 years of age ${ }^{10}$. Figure 1 documents how the answers to each of the questions we use change across the three waves.

The first panel of Figure 1 shows how the country wave effects of attitudes toward women (the answer to the question "Do you think that a woman has to have children....", coded so that higher values correspond to more liberal attitudes towards women working) change across the three waves in each country — we collect countries in three clusters plus one for Denmark, and one for Japan ${ }^{11}$. This is important because our identification comes from the time variation of these variables. The pattern for all groups shows a shift toward "conservatism" (meaning that the country-wave effects of the answers shift towards a view that women need to have children to be fulfilled) from 1980 to 1990, followed by a shift in the opposite direction in the following decade. Such shifts are consistent, possibly, with a political shift from progressive to conservative (Reagan in the US, Thatcher in the UK, ...) that occurred in many countries at the beginning of the 1980s, followed by a shift toward more progressive politics (Clinton, Blair...) in the following decade. Note that, within this common pattern, the shifts occur at different rates and are reflected in the slopes of the lines being different for each cluster. Denmark appears not to rebound from a shift toward more conservatism.

The other panels of Figure 1 repeat the exercise for the country-wave effects of the other two attitudes (higher values reflect greater value placed on youth independence or on the importance of holidays). In each case the data show that all measures of culture we use are time varying. The value placed on youth independence appears to increase during the 1980's and decrease in the 1990's, although at different rates in each country. The evolution of attitudes towards holidays does not display any common pattern, although the importance of generous holidays increases for all countries between 1980 and 1990 and decreases or remains stationary for most countries from 1990 to 2000 .

Finally in Figure 2 we report the evolution of the employment rate for women and for youth, and average annual hours ${ }^{12}$. Employment rates for women increase in every region, over our sample,

\footnotetext{
${ }^{9}$ We group immigrants from some countries in the same clusters of origin in order to have enough observations in each group when we run the probit regressions (see the Data Appendix for more details).

${ }^{10}$ For most countries the attitude variables we use are available for all three waves. For some countries, for only two waves. Details, including the precise timing of the surveys, are contained in the Data Appendix.

${ }^{11}$ The countries belonging to each cluster are: Anglo-Saxon (Canada, Ireland,UK and US), European continental (Belgium, France, Germany, Netherlands), Mediterranean (Italy, Spainl). The countries for which we do not have 3 observations are shown separately but they are given the same colour of the cluster they are commonly associated with.

${ }^{12}$ For most countries, all these variables represent four year averages over the period 1981-1984, 1990-1993, 1999-
} 
with the only exception of the Nordic countries (where women participation has been historically very high) and Japan, where they have been stable in the 90's. The pattern of employment rates for the youth varies more across countries: it falls by 15 percentage points in the Mediterranean countries, more quickly in the 80's; it falls in the Nordic countries in the 80's and then it remains stable in the 90's; it falls and then recovers in the Anglo-Saxon countries. Average hours of work tend to decrease in the 80's, although at a different pace in each country. In the 90's the rate of decrease tends to be smaller in many countries, but not in all of them.

The bottom line is that our measures of attitudes are not constant over time and vary over time at different rates. Their effect can thus be potentially identified separately from that of other cultural traits that instead are constant over time and therefore can not be identified separately from other non time-varying country characteristic. Whether there is a significant correlation between labor market outcomes and our time varying measure of cultural attitudes, and whether it can be given a causal interpretation (going from attitudes to outcomes), is the issue we address in the following sections.

\section{$3 \quad$ Estimation strategy}

In the previous section we have discussed the variation across countries and over time of a country and year specific measure of culture based on the country $\backslash$ wave effects in a cross sectional probit equation for each attitude estimated on individual data for all countries at each point in time. Let $A_{c t}$ denote this survey-based measure of country's $c$ cultural attitudes at time $t$. We intend to estimate the effect of $A_{c t}$ on economic outcomes, denoted by $Y_{c t}$, where $Y_{c t}$ is determined by the following equation

$$
Y_{c t}=\alpha_{0}+\alpha_{1} Y_{c t-1}+\alpha_{2} A_{c t}+\alpha_{3}^{\prime} X_{c t}+\Psi_{c}+\Psi_{t}+\varepsilon_{c t}
$$

$\Psi_{t}$ denote common time effects. The country specific and the idiosyncratic components of the error term, $\Psi_{c}$ and $\varepsilon_{c t}$, are independently distributed across $c$, and have the standard error component structure in which $E\left(\Psi_{c}\right)=0, E\left(\varepsilon_{c t}\right)=0, E\left(\Psi_{c} \varepsilon_{c t}\right)=0$ and $E\left(\varepsilon_{c t} \varepsilon_{c s}\right)=0$ for $\left.s \neq t\right)$. $X_{c t}$ are other, time-varying variables that may influence the outcome of interest. They include time varying institutions, policies and other time varying structural characteristics of a country. For the purpose of our discussion here we will assume that the variables in $X_{c t}$ are either strictly exogenous or predetermined, i.e. they are either not correlated with $\varepsilon_{c t}$ at any time period, or they are not correlated with contemporaneous or future values of $\varepsilon_{c t}$, but may be correlated with its past values. The latter assumption is more appropriate for policy and institutional variables that may evolve in response to outcomes and attitudes, but with a lag. Actually, in estimation, we will allow some labor market policies, such as unemployment benefits, to be affected immediately by labor market conditions, but we suppose this is not the case here, purely for ease of exposition.

2002. We will also use data for the 1972-1975 period in models with the lagged dependent variable. See the data appendix for further details. 
If there is persistence in $Y_{c t}$ that goes beyond the one generated by the fixed effect $\Psi_{c}$ or the persistence of the regressors, this justifies the inclusion of the lagged dependent variable in the equation. This seem a very plausible hypothesis for employment rates and hours. The identification problem in estimating (1) arises because attitudes are likely to be correlated with the shock to the labor market outcome equation $\left(E\left(A_{c t} \varepsilon_{c t}\right) \neq 0\right)$. As an example, assume that $A_{c, t}$ is determined by the following equation

$$
A_{c t}=\tilde{\gamma}_{0}+\sum_{j=1}^{J} \tilde{\gamma}_{1 j} A_{c t-j}+\tilde{\gamma}_{2} Y_{c t-1}+\tilde{\gamma}_{3} Y_{c t}+\tilde{\gamma}_{4}^{\prime} Z_{c t}+\tilde{\Phi}_{c}+\tilde{\Phi}_{t}+\tilde{\nu}_{c t}
$$

where $A_{c t-j}$ denotes past attitudes and $Z_{c t}$ is a vector of additional explanatory variables. $\tilde{\nu}_{c t}$ shares the same characteristics of $\varepsilon_{c t}$, including lack of serial correlation. The variables in $Z_{c t}$ are institutional and policy variables, as well as other variables that may affect labor market attitudes, such as the advances in the technology of contraception and their diffusion, the waxing and waning of broad cultural movements, such as the feminist movement, or of political tendencies towards more conservative or liberal views. The variables in $Z_{c t}$ (like those in $X_{c t}$ ) are either strictly exogenous or predetermined (uncorrelated, in this latter case, with present or future values of $\tilde{\nu}_{c t}$ and $\varepsilon_{c t}$ ).

Equation (2) makes clear that attitudes respond to both present and past labor market outcomes. Using equation (1) to obtain the reduced form for $A_{c t}$ (substituting out $Y_{c t}$ ), we get

$$
A_{c t}=\gamma_{0}+\sum_{j=1}^{J} \gamma_{1 j} A_{c t-j}+\gamma_{2} Y_{c t-1}+\gamma_{3}^{\prime} W_{c t}+\Phi_{c}+\Phi_{t}+\nu_{c t}
$$

where the $\gamma^{\prime} s$ are a function of the $\widetilde{\gamma}^{\prime} s$ and $\alpha^{\prime} s$. $W_{c t}$ is the union of $Z_{c t}$ and $X_{c t}$. Note that $\nu_{c t}$ is a linear combination of $\varepsilon_{c t}$ and $\tilde{\nu}_{c t}\left(\nu_{c t}=\left(\tilde{\gamma}_{3} \varepsilon_{c t}+\tilde{\nu}_{c t}\right) /\left(1-\tilde{\gamma}_{3} \alpha_{2}\right)\right)$ and hence is certainly correlated with $\varepsilon_{c t}$, even if $\tilde{\nu}_{c t}$ and $\varepsilon_{c t}$ are uncorrelated. This is one source of the endogeneity problem we have referred to and it would not be there if attitudes did not respond to contemporaneous labor market outcomes. Provided $1-\tilde{\gamma}_{3} \alpha_{2}$ is positive, a positive $\tilde{\gamma}_{3}$ would lead to a positive correlation between $A_{c t}$ and $\varepsilon_{c t}$.Non zero correlation between $\tilde{\nu}_{c t}$ and $\varepsilon_{c t}$ is another source of endogeneity.

It is likely that attitudes measured through survey responses on women role in the family and in the workplace are effected not only by past but also by contemporaneous employment experiences. For instance, high employment rates for women may reinforce the sense that having a role in the formal labor market is both rewarding and acceptable, and may lessen the perception of motherhood as a necessary component of fulfilment. ${ }^{13}$ Moreover, it is plausible that the unobservables that lead to a more favorable response towards women working will be positively correlated with the unobservables that lead to higher women employment rates. Not addressing the endogeneity issues is likely to lead to an overestimate of the effect of attitudes towards women in the workplace on employment outcomes. The possible endogeneity of the attitude variable concerning the importance of independence as a positive trait for youth is, perhaps, less clear-cut. Even here, however, one

\footnotetext{
${ }^{13}$ It is true that we control - in the regression generating the country-wave attitude variables - for an individual's employment status. However this is not enough to eliminate the endogeneity problem because individual responses may be affected not only by one's experience, but also by aggregate conditions.
} 
can imagine that a buoyant youth labor market may quickly affect perceptions. The attitude about the importance of generous holidays is also very likely to respond to shocks to actual hours of work, although it is not clear in which direction. Working longer hours may be associated with an increase in the desire for leisure, through, for instance, an income effect or due to stress when annual hours actually worked get closer and closer to the bound represented by the total hours available in one year. However, if hours and wages are positively associated, longer hours would be associated with a demand for less leisure, through the substitution effect.

What can be done to address this endogeneity issue? Equation (2) offers some suggestions. Today's attitudes depend upon past attitudes and past outcomes that are not correlated, given our assumptions, with today's shock to the outcome variable. Moreover, there may be some other, deeper and slower moving attitudes that evolve over time, but respond only with a lag to economic outcomes in the labor market, such as religious beliefs and, perhaps the degree of trust. ${ }^{14}$ These deeper (or different) attitudes are assumed not to have a direct effect on labor market outcomes. They are determined by an equation similar to (2), but with the crucial difference that they respond to outcomes only with a lag so that the coefficient $\tilde{\gamma}_{3}$ of $Y_{c t}$ equals zero. Moreover, it is less likely that the shocks in the structural equations for these attitudes are correlated with those in the outcome equation. The contemporaneous values of these deeper attitudinal variables (call them $\left.A_{c t}^{d}\right)$ can, therefore, be considered predetermined in the outcome equations $\left(E\left(A_{c s}^{d} \varepsilon_{c t}\right)=0\right.$ for $s \leq . t$ ). These deeper (or different) cultural attitudes are also likely to be correlated with the labor market attitudes we are investigating, $A_{c t}$, for instance because they share some of the determinants contained in $Z_{c t}$ in equation (3), or because both of them respond to lagged economic outcomes. Another option, with identical consequences from our point of view, would be to assume that labor market attitudes are determined by deeper attitudes (i.e.. assuming that $A_{c t}^{d}$ is included in $Z_{c t}$ ) and to continue to maintain the assumption that the latter are uncorrelated with contemporaneous labor market shocks.

Using lagged values of attitudes, lagged outcomes, or contemporaneous values of the (predetermined) deeper attitudes as instruments in the context of the within estimator of equation (1) is, however, not legitimate, given the shortness of the panel. Nevertheless, one can use the GMM difference estimator proposed by Arellano and Bond (1991) and the system estimator of Blundell and Bond (1998) to address the endogeneity issue. The system estimator (under the appropriate assumptions about initial conditions) is an appealing choice if attitudes are persistent. More precisely we will use appropriately lagged values of the levels of $Y_{c t}, A_{c t}$ and $A_{c t}^{d}$ for the equation in difference and of their differences for the equation in levels. Taking first differences of (1) we obtain

$$
\Delta Y_{c t}=\alpha_{1} \Delta Y_{c t-1}+\alpha_{2} \Delta A_{c t}+\alpha_{3}^{\prime} \Delta X_{c t}+\Delta \Psi_{t}+\Delta \varepsilon_{c t}
$$

$Y_{c t-j}, A_{c t-j}$ with $j \geq 2$ and $A_{c t-j}^{d}$ with $j \geq 1$ are legitimate instruments for $\Delta Y_{c t-1}$ and $\Delta A_{c t}$,

\footnotetext{
${ }^{14}$ Fortin (2008) uses attitudes towards premarital sex as instruments for gender role attitudes. Guiso, Sapienza and Zingales (2006) employ the percentage of adherents of various religious denominations as an instrument for thrift in a regression with aggregate saving as the dependent variable in a pooled OLS regression.
} 
given the serially uncorrelated nature of $\varepsilon_{c t}$. The treatment of $X_{c t}$ will depend upon the nature of the variables. Institutions and policies cannot be treated as strictly exogenous variables: it may be more plausible to assume that they are endogenous or predetermined, in which case they also need to be instrumented. We will address this issue in the GMM result section (see Section 6). In the system estimator the orthogonality conditions for the differenced equation are augmented by the orthogonality conditions for the level equation. Blundell and Bond $(1998,2000)$ show that under appropriate assumptions about the initial conditions, we can use $\Delta Y_{c t-1}, \Delta A_{c t-1}$, and $\Delta A_{c t}^{d}$ as instruments for $Y_{c t-1}$ and $A_{c t}$ in the equation in levels. (1).

Another complementary strategy to address the endogeneity issue is to use the attitudes of immigrants into the US to instrument for the attitudes in the country of origin (excluding the US). Algan and Cahuc (2008) use the attitudes of immigrants into the US in a reduced-form framework. They replace the country-level attitudes for Trust in 2000 and in 1935 with the corresponding inherited attitudes of second (or higher) generation immigrants in the US. The unobservable country-level attitudes in 1935 are those inherited by second generation Americans born before 1910, of third generation born before 1935, etc.

Given the assumptions embodied in our model - and also given the higher frequency of the observations for the labor market variables we employ, approximately ten years interval - we consider a different approach that still uses information on the attitudes of US immigrants. Basically, we will use the contemporaneous values of the attitudes of immigrants in the US from a given country at a given point in time as an instrument for the attitudes of the country of origin at the same time (as opposed to the inherited attitudes used in Algan and Cahuc, 2008).

More specifically, assume that $A_{c t}^{U S}$ denotes the country of origin $(c)$ and period $(t)$ component of attitudes towards gender, youth and leisure, or other attitudes potentially correlated with labor market attitudes, of first or higher generation immigrants to the US, after controlling for personal characteristics. One could include in the sample all immigrants, except those who have come to the US after 1980, so that none of them has experienced the labor market in the home country during the period we use for estimation (1980-2000). If one is worried about the possibility is that first generation immigrants in the US may maintain close information or family ties with the country of origin and be affected by the evolution of attitudes and outcomes there, one can exclude first generation immigrants from the sample. We will follow the latter strategy and focus on second or higher generation immigrants. Assume that their attitudes, $A_{c, t}^{U S}$, are determined by:

$$
A_{c t}^{U S}=\theta_{0}+\sum_{j=1}^{J} \theta_{1 j} A_{c t-j}^{U S}+\theta_{2} V_{c t}^{U S}+\Phi_{t}^{U S}+\Phi_{c}^{U S}+\nu_{c t}^{U S}
$$

where $V_{c t}^{U S}$ are additional observable US, time and country of origin specific determinants of US attitudes. $\Phi_{c}^{U S}$ is a time invariant effect specific to the country of origin. $\Phi_{t}^{U S}$ represents a US specific factor that has a common effect, independently of country of origin. Finally, $\nu_{c t}^{U S}$ is a serially uncorrelated random shock.

The first issue at stake is whether the time evolution of attitudes in the country of origin and 
those of immigrants to the US are correlated. It is plausible to assume that this may be the case because some of the country-of-origin specific determinants of immigrants attitudes $\left(V_{c t}^{U S}\right)$, are correlated with the determinants of attitudes in the country of origin (such as $Z_{c t}$ or present or past $Y_{c t}$ ). This is likely to be the case for variables representing the group specific effect of broad cultural or political changes and technological innovations (feminist movement, swings towards political conservatism, innovation in contraception technology, etc.). For instance, changes in the contraception technology available are likely to be correlated across countries and to generate correlated effects on the attitudes of country $c$ and on the attitudes of immigrants in the US from country $c$ because they are filtered through a partly common cultural background, even though law and regulations differ across countries. ${ }^{15}$ A possible source of concern is that a selection issue may affect the emigration decision in the sense that people who left may be those who are more independent and less attached to the values of the country of origin (Alesina and Glaeser (2004), Alesina and Giuliano (2007)). Ultimately, the data will suggest whether the evolution of the attitudes of immigrants into the US is informative about the evolution of attitudes in the country of origin.

The second issue is whether $A_{c t}^{U S}$ is uncorrelated with the error term in the outcome equation in country $c$ at time $t$. Clearly $A_{c t}^{U S}$ is likely to be correlated with the country effect in the outcome equation, $\Psi_{c}$, since the latter contains, among other elements, time invariant and country specific components of culture that are partly transmitted to US immigrants ( and are represented by $\Phi_{c}^{U S}$ in (5).However, it is plausible to assume that after conditioning on time varying country variables, $X_{c t}$ (that will include a country specific measure of business cycle conditions, policies and institutions) and a common time effect $\Psi_{t}$, the idiosyncratic shocks to labor market outcomes in each country, $\varepsilon_{c t}$, are not correlated with $A_{c t}^{U S}$. Under these assumptions, it is legitimate to use (in countries other than the US) $\Delta A_{c t}^{U S}$ as an instrument for $\Delta A_{c t}$ in the difference equation and for $A_{c t}$ in the level equation.

In any case, in Section 6 we will report the Hansen-Sargan test of over-identifying restrictions to test the lack of correlation between the instruments and the error term in the outcome equations. In Section 5 we will investigate the correlation between labor market attitudes and the potential instruments and we will assess their relevance by estimating the appropriate first stage regressions. Recall that in the GMM system estimator we have two sets of first stage regressions: one in differences and one in levels. Moreover, when a large number of cross sectional observations are available, in each first stage regression one can allow the coefficients to vary in each cross section. For the equation in difference, (4), assuming $\alpha_{3}^{\prime}$ equal zero for simplicity, the first stage regression for $\Delta A_{c t}$ is a variant of

$$
\Delta A_{c t}=\pi_{0 t}^{d}+\pi_{1 t}^{d} Y_{c t-2}+\pi_{2 t}^{d} A_{c t-2}+\pi_{3 t}^{d} A_{c t-1}^{d}+\pi_{4 t}^{d} \Delta A_{c t}^{U S}+\omega_{c t}^{d}
$$

where further lags of $Y_{c t-2}, A_{c t-2} A_{c t-1}^{d}$ and $A_{c t}^{U S}$ could also be included, if available. For the

\footnotetext{
${ }^{15}$ Note that US shocks common to all groups, $\Phi_{t}^{U S}$, provide a time variation in attitudes that is not useful for instrumenting $A_{c t}$ because it is completely absorbed by the period dummy in the outcome equation, $\Phi_{t}$.
} 
equation in levels the first stage regression for $A_{c t}$ is a variant of

$$
A_{c t}=\pi_{0 t}^{l}+\pi_{1 t}^{l} \Delta Y_{c t-1}+\pi_{2 t}^{d} \Delta A_{c t-1} \pi_{3 t}^{l} \Delta A_{c t}^{d}+\pi_{4 t}^{l} \Delta A_{c t}^{U S}+\omega_{c t}^{l}
$$

We have experimented both with time varying and time invariant coefficients, and we have settled in favor of the latter option, given the limited number of cross sectional observations at our disposal.

There is a final issue we need to address. All the discussion above has been conducted under the implicit assumption that we can perfectly observe the attitudes towards gender, the young, or leisure. Assume instead that we can observe all attitudes only with an error so that $\widetilde{A}_{c t}=$ $A_{c t}+\mu_{c t}^{A}, \widetilde{A}_{c t}^{d}=A_{c t}^{d}+\mu_{c t}^{A^{d}}$, and $\widetilde{A}_{c t}^{U S}=A_{c t}^{U S}+\mu_{c t}^{A^{U S}}$, where $\sim$ denote measured variables and the $\mu^{\prime} s$ classical serially uncorrelated measurement errors. This would lead to attenuation bias when the outcome equations are estimated by least squares procedures. In terms of our instrumental variable procedure we now need to assume that measured deep attitudes or measured attitudes of US immigrants are not correlated both to the shock to the outcome equation, $\varepsilon_{c t}$, as well as with the measurement error for attitudes towards gender,youth and leisure, $\mu_{c t}^{A}$. This requires, among other things, the measurement errors to be uncorrelated with each other. ${ }^{16}$

\section{Within estimates}

In this section we present and discuss a set of results obtained by estimating an equation for the employment to population ratio for women $\left(e p r_{-} w\right)$ and youth $\left(e p r_{-} y\right)$ and for average annual hours of work (hours), using the Within (or least square dummy variable, LSDV) estimator. The explanatory variables for $e p r_{-} w$ include cultural attitudes towards the need of having children for a woman to feel realized (women_cn), or towards the priority of male employment when jobs are scarce (women_jp). The former is available for up to three waves, while the latter is available only for a maximum of two waves. The variables are derived as the country/wave effect described in the previous section and are coded in such a way that increasing values denote a more progressive attitude towards women For youth employment rates, the cultural variable captures the importance given to youth independence as a desirable trait $($ youth_i).

The within (least square dummy variable, LSDV) estimator allows for country specific and time invariant effects. Such effects capture both time invariant cultural traits and time invariant institutions, in addition to other time invariant country characteristics that may affect the employment or hours outcomes. They also control for country specificity in interpreting the survey question and for lack of cross country comparability of the dependent variable. This is not a problem for women and youth employment rates, but is a potential problem for the hours of work series available. ${ }^{17}$

\footnotetext{
${ }^{16}$ More precisely, when using the attitudes of US immigrants as instruments, for instance, one need to assume lack of correlation between (i) $A_{c t}^{U S}$ and $\varepsilon_{c t}$, as before, (ii) between $\mu_{c t}^{A^{U S}}$ and $\varepsilon_{c t}$, and (iii) between $\mu_{c t}^{A}$ and both $A_{c t}^{U S}$ and $\mu_{c t}^{A^{U S}}$. Parallel assumptions are required for deep attitudes.

${ }^{17}$ The OECD warns that the series for hours they have produced and that we are utilizing is homogeneous through time within each country, but is not comparable across countries. This emphasizes the importance of including a
} 
The main drawback of the within estimator is the fact that it does not recognize and address the endogeneity of the cultural variables discussed in the previous section. The latter reflect phenomena unrelated to contemporaneous labor market experience (i.e. the "women revolution" or the technological improvement in contraception), but are also shaped by contemporaneous experiences or shocks in the labor market. In other terms, they are almost surely correlated with the stochastic shock in the employment and hours equations.

Another drawback of the within estimator is that one cannot properly address the issue that employment and hours outcome are likely to evolve gradually over time This would require the inclusion of the lagged dependent variable as an additional regressor. Yet, in this case the within estimator would not yield a consistent estimate of its coefficient, and of the coefficients on the other variables, even if the latter were strictly exogenous, since the time dimension is small (equal to three in our case). ${ }^{18}$

Yet, the within estimates are a useful starting point because they address some of the issues we are interested in (although not all) and have been used in the paper that is most closely related to ours, Algan and Cahuc (2007), who analyze the employment rates for women and youth in OECD countries using three waves of the WSS survey between 1980 and 2000. ${ }^{19}$ That paper uses women_jp as the explanatory variable for the equation for women, and the same attitudinal variable we use for youth (youth_i). Fortin (2005), instead, presents estimates for the women employment rate in OECD countries in a specification that also considers multiple waves (roughly 1990, 1995 and 2000), and uses both women_jp and a variable similar to our women_cn (being a housewife is fulfilling), but does not include country dummies.

As additional controls we include in the equations "structural" variables, such as women education $\left(e d u_{-} w\right)$, the share of services in value added (serv_va), the fraction of population above 65 ( $\left.p o p \_65\right)$, the average number of children per woman (children). We also include proxies for (time varying) policies or labor market institutions, such as unemployment benefits (ben), employment protection legislation (epl), union density (udens), taxes on labor income (tax_wedge). We also control for the stage of the business cycle through a measure of the gap between actual and potential output (gap). In the within regressions these variables are all treated as exogenous, although in reality they may be correlated with present or past shocks in the outcome equations. The inclusion of a large menu of structural, institutional and policy variables allows us to isolate the direct effect of attitudes on outcomes All equations also include a wave dummy to capture common time effects.

The results for women employment rates using women_cn as an explanatory variable are reported in Table 2. One main conclusion that can be derived from these results is that the coefficient of the attitudes variable is significant in all specifications, although its value tends to decrease somewhat when one adds additional controls. Cultural attitudes about the need of having children for

country fixed effect in the regression.

${ }^{18}$ See Nickell (1981). In our case we have observations for three periods at ten years intervals for the attitude variables (from 1980 to 2000) and observations for four periods (from 1970 to 2000) for outcome variables.

${ }^{19}$ Algan and Cahuc (2005) also analyze the employment rate for older workers as a function of attitudes towards forcing older workers to retire when jobs are scarce. We do not because the latter variable is only available for the 1990 wave of the WWS and for the 1995 wave for a smaller set of countries. 
a woman to feel fully realized are positively associated with the employment outcomes for women. We will assess whether this positive association can be given a causal interpretation in the next section.

We start in column (1) from a simple specification with only women_cn. We then add gap in column (2) (and in all remaining columns). In column (3) we add the structure variables, while in column (4) we add the policy and institutional variables. Column (5) contains both sets of variables, while in column (6) we report a more parsimonious model containing the more significant variables among the structure, policy, and institutional variables.

In most specification the gap variable is significantly and positively associated with the women employment rate, as one would expect. Among the structural variables, the relative size of the service sector displays a positive and significant coefficient, in one specification, reflecting the relatively greater employment opportunities for women in this sector. Not surprisingly, the coefficient for the number of children is, instead, always negative and significant, as well as the percentage of the population above 65 . The effect of this latter variable could go either way a priory: grandparents can provide baby-sitting services, but also may increase the demand for care, that may fall disproportionately on women. The latter effect seems to dominate. Employment protection, the generosity of employment benefits and union density all have a negative and significant coefficient in the specification without the structure variables. Taxes and employment protection are the only policy variables negatively associated with employment rates in the more general specification including also the structure variables. Surprisingly, women education is not significant in this specification.

The overall impression is that cultural attitudes, policies, institutions, and structure all matter as determinants of the women employment rate. The effect of culture decreases, but remains large. For instance, in the specification of column (5) an increase from the first to the third quartile of the distribution of women_cn is associated with an increase in the employment rate for women of approximately 5.7 percentage points. This represents a third of the difference between the first and the third quartile of the employment distribution (18.1 percentage points). An increase in $e p l$ from the first to the third quartile is associated with a decrease of 13.34 percentage points in $e p r_{-} w$. A similar change in taxation is associated with a decrease in $e p r_{-} w$ of approximately 14 percentage points. Finally changes from the first to the third quartile in the number of children or the population dependency ratio are associated with a decrease in $e p r_{-} w$ of 3 percentage points each.

Taking these results at face value and comparing them with those in Algan and Cahuc (2007), one concludes that Algan and Cahuc overstate the dominance of culture as a determinant of the employment rates of women and understate the role of policies. The direct effect of culture is sizeable, but policies matter even more. It is certainly possible that the effect of culture goes through policies and institutions, however the direct effect, while important, is not overwhelming. Demographic variables are also quantitatively important. In the specification with the attitudinal variable based on job priority for men (women_jp), which is the variable actually used by Algan 
and Cahuc, its coefficient is also always significant (See Table 3). Most of the policy, institution and structural variables are also significant. ${ }^{20}$ However, the model suffers from a severe case of overfitting, given the small number of observations, since no data are available for women_jp in the 80 's. ${ }^{21}$. Therefore, we should attach less weight to this specification and we will not pursue it further.

In Table 4 we report the within estimates for the youth employment rate. Attitudes towards child independence as a positive trait (youth_i) are not significantly associated with youth employment rates. In the specification without controls the coefficient of this variable is actually negative and significant, suggesting the presence of specification or estimation issues. Youth employment increases significantly during expansions, and is negatively and significantly associated with taxation and (in one specification) with employment protection legislation. The estimated coefficient on unemployment benefits is positive and significant, which is surprising. The negative coefficient of the education variable probably simply reflects the fact that with higher levels of education, young adults remain out of the labor market longer. Certainly, there is no support from these results for the proposition that cultural attitudes are important determinants of youth employment outcomes - and the role of policies presents some puzzling aspects.

Finally, in Table 5 we report the results for hours of work. Listing generous holidays as an important attribute of a job (holidays) is not significantly associated with actual annual hours. In addition to gap, other important variables are employment protection legislation and women employment rate (both with a negative coefficient). More employment protection is often associated with restrictions on work hours. Moreover, women are more likely than men to have part time jobs, which explains the negative sign of $e p r_{-} w$. Finally the association between hours and the relative importance of the service sector represents is positive. This result could reflect the fact that the larger the service sector the more likely it is for some groups (students for instance) to work part-time, thus increasing overall hours worked in the economy.

In terms of the relative quantitative importance of policies, consider that the third quartile of the distribution of hours is 14.3 percent higher that the first quartile. An increase in epl from the first to the third quartile is associated with a decrease of 12 percent in hours of work.

Because of all the econometric issues we have outlined above it is premature to draw any definitive conclusion from these within regressions. Yet, conditional on structure and policies, our within result do not lend support to the hypothesis that cultural attitudes play an overwhelming role in explaining the evolution over time of employment or hours. Gender attitudes appear to be important for women employment rates, but so are other policy or structural variables.

\footnotetext{
${ }^{20} \mathrm{An}$ increase in women_jp from the first to the third quartile is associated with a increase of 4.8 percentage point in $e p r_{-} w$. An increase in epl from the first to the third quartile is associated with a decrease of 6.6 percentage points in epr_w. This is similar to what we have obtained with women_cn.

${ }^{21}$ Algan and Cahuc (2007) use three waves for the outcome and attitude variable (early 80's, early 1990's and late 1990's), but it is not clear how the data for women_jp for the 80's were obtained, given that the question was only asked in 1990, 1995 (for a smaller set of countries) and 2000.
} 


\section{Choice of instruments}

In order to address the endogeneity issues discussed in Section 3, we will use "deeper attitudes" in the country of residence - attitudes towards trust and belief in God - and attitudes toward trust, pre-marital sex and women work among US immigrants, as potential instruments. In order to assess whether these variables are indeed good instruments we need to check whether they contain information about attitudes towards women, child independence and the importance of generous holidays, our proxies for a country's "culture". Ultimately, it will be the data, in the first stage regressions, to tell whether the evolution of these variables matters for women_cn, youth_i, and holidays, but it is useful to start thinking about reasons why such correlations may arise.

Consider first the attitudes towards trust. It has been suggested that lack of trust is typical of hierarchical societies. ${ }^{22}$ A hierarchical structure of society is likely to be associated with an emphasis on traditional gender roles within the family. Moreover, in hierarchical societies families tend to be relatively more important, inducing people to engage in more non-market, family centered activities. ${ }^{23}$ Finally, in such an environment, citizens may think that they have less control on their life and that individual effort is not likely to pay off, leading to a reduced importance of independence as a desirable characteristic of the young. In addition to trust in the country of residence, we will also use trust of US immigrants as an instrument.

Consider next the question about beliefs in God and religious beliefs in general. It has been suggested that religious beliefs may signal more conservative values, among them the idea that women should be subordinated to men and naturally belong to the home. ${ }^{24}$ It has also been suggested that this may be particularly true for Christian traditions with an emphasis on hierarchy, such as Roman Catholicism and Eastern Orthodoxy. ${ }^{25}$ Among Protestants, Max Weber's hypothesis would imply a positive correlation between religious beliefs and work ethic, with more emphasis on work versus leisure and, possibly, a more favorable view of women employment. ${ }^{26}$ However, there is evidence that for Catholics there has been a change in the nature of religious beliefs and their association with attitudes towards women after Vatican II. ${ }^{27}$ All this suggests that beliefs in God or other indices of religiosity are instruments worth exploring, particularly if interacted with the historically dominant religious affiliation of each country. ${ }^{28}$

Further, consider the question about pre-marital sex among US immigrants. More conservative values towards premarital sex could signal more importance attached to the role of women in the

\footnotetext{
${ }^{22}$ See Banfield (1958) and Tabellini (2008b).

${ }^{23}$ See Algan and Cahuc (2006).

${ }^{24}$ Guiso, Sapienza and Zingales (2003) present micro evidence that the presence of religious beliefs and their intensity is associated with less favorable attitudes towards women working.

${ }^{25}$ See, for instance Luperini et al. (1997) and Archimandrite (1981, p.38).

${ }^{26}$ Weber (1930).

${ }^{27}$ See Guiso, Sapienza and Zingales (2003).

${ }^{28}$ It is important to note that our "deeper" attitudes are time-varying, even if it may take some time for them to evolve. For instance, beliefs in God (or participation in organized religious activities) can change in response to economic development (secularization hypothesis) and to changes in competition among religion providers ("supplyside" theory) (see Barro and McClearly (2003)) For a discussion of the determinants of trust see, instead, Alesina and La Ferrara (2002).
} 
home relative to their role in the workplace ${ }^{29}$. Moreover, if more conservative attitudes toward premarital sex reflect a more traditional and hierarchical society, the effect on attitudes toward leisure will be similar to those outlined above when we were discussing the attitudes towards trust.

Finally, answers to the question asked of US immigrants "Do you approve or disapprove of a married woman earning money in business or industry if she has a husband capable of supporting her" are informative about attitudes towards the "male breadwinner" model, and suggest themselves as a natural instrument for gender attitudes in the country of residence. ${ }^{30}$

In Table 6 we present information about the relevance of these instruments in explaining the level, or change in women_cn, youth_ $i$, and holidays. We do not report all our experiments and focus on the more promising ones, or on some of those that are indicative of the challenges one faces. In the first part of the table we focus on deeper attitudes in the country of residence. Recall that these are treated as predetermined variables. In the first row we present the $F-t e s t$ of joint significance of (the country/wave effects of) belief in God lagged once, interacted with the historically dominant religious affiliation of each country, in a regression of $\Delta$ women_cn on the lagged religious belief variables (God for short) and time dummies. We then report the $F-t e s t$ obtained in the regression of women_cn on the lagged change of such religious belief variable and time dummies. The results suggest that beliefs in God are informative for the level of women_cn, but not for its change. The marginal significance level of the $F$ - test (in parenthesis) is 0.0021 in the first case and only 0.287 in the second. Adding to the information reported in the table, note that an increase in the percentage of believers in historically Catholic countries (there are no Eastern Orthodox countries in our sample) or in Japan (the only non Catholic or non Protestant country in our sample) is associated with a significantly lower level of women_cn, while this is not the case for the historically Protestant countries. In the third line we repeat the same exercise for holidays. The results suggest that there is useful information in religious beliefs for the level and change of holidays, although more for the former than the latter ${ }^{31}$. In the equation for the level of holidays an increase in belief in God in historically Protestant countries is significantly and negatively associated with holidays, while there is no significant association for Catholic countries (and a positive and significant one for Japan). The difference between Catholic and Protestant countries is broadly consistent with the arguments summarized above. Finally, in the second row of the table we report the correlation coefficient between youth_i and trust. Lagged values of trust contain very little information about the level or the change in youth_ $i$. This is just an

\footnotetext{
${ }^{29}$ Fortin (2008) uses contemporaneous individual attitudes towards sex and politics in the country of residence as an instrument for family attitudes in an equation that explains a woman's participation decision in the United States. We have experimented with the answers to a question in the WWS about the importance of happy sexual relationship for a marriage, but they did not appear to contain useful information for any of the attitudinal variables we use as regressors.

${ }^{30}$ We have also experimented with the attitude of immigrant towards women in politics. The answers to this variable seem to contain some information about attitudes towards women work in the country of residence, but not as much as the answers to the questions in the text.

${ }^{31}$ In the equation for the change in holidays, the low value of the marginal significance level of the $F-t e s t$ is entirely due to the significance of the coefficient of the interaction of God with the Japan dummy. Beliefs in God do not matter for Protestant or Catholic countries.
} 
example of the difficulty of finding deeper attitudes that are correlated with attitudes towards child independence.

In the second part of Table 6, we study the correlation of attitudes in the various countries with those of US immigrants from the same countries: imm_fework denotes the attitude towards women working even when the husband could support her, imm_sex denotes the attitude towards pre-marital sex. The answers are coded so that higher values of these variables reflect more liberal attitudes. Recall that changes in the attitude of immigrants are treated as exogenous in both the level and difference outcome equations. We report the relevant correlation coefficients, after partialling out the effect of time dummies. Both $\Delta i m m_{-}$fework and $\Delta i m m_{-}$sex are positively and significantly associated with the change in women_cn, but not with its level. Change in immigrant trust is negatively and almost significantly associated with the level youth_ $i$. Changes in $i m m_{-}$trust and $\mathrm{imm}_{\text {_ }}$ sex are significantly associated (at around the $5 \%$ level) with the change and level of holidays.

Summarizing, the first set of instruments (deeper attitudes) contain useful information to estimate the level equations for epr_w and hours. The attitudes of US immigrants contains useful information for the difference equation for epr_w and hours, and for the level equation of the latter variable. Finding appropriate attitudinal instruments for youth_i remains an open issue.

In the last part of Table 6 we report the $F$ - test for the first stage regressions containing both the deeper attitudes, the attitude of US immigrants and lagged outcomes (details on exact variables included is contained in the table). The (lagged) outcome variable is included to capture the idea that attitudes can be affected by outcomes. The results confirm that the instruments for our measure of gender attitudes and of attitudes towards holidays are informative both in the level and difference equation, while it is very hard to find relevant instruments for our measure of attitudes towards youth independence, particularly for the difference equation. Increases in past level of epr_w are positively and significantly associated (at the $5 \%$ level) with more liberal attitudes (in levels) towards women. Past increases in hours work have a positive effect (significant at the $10 \%$ level) in the first stage regression for the level of holidays, suggesting that working longer hours is associated with a greater desire for leisure, through, for instance, an income effect or due to stress.

\section{GMM estimates}

In Table 7 we present the GMM estimates of the equation for women's employment rate. In columns (1) through (7) we use the system estimator with belief in God (interacted with the historically prevalent religious affiliation, and appropriately lagged) plus $\Delta i m m_{-}$fework and $\Delta i m m_{-}$sex as instruments, in addition to the appropriately lagged values of epr_w and women_cn (and of the additional regressors). Relative to the idiosyncratic component of the error term, gap, ben, ser_va and children are treated as endogenous, edu_w, tax_wed, udens and epl, as predetermined, and pop65 as exogenous. Given the limited number of observations we have constrained the coefficients 
of the first stage regression to be equal across the three waves. For the same reason, we have used only the shortest lag allowed for each variable as instrument. The results suggest that women_cn remains a significant determinant of the evolution of women employment rates in all specifications, even when instrumented. Another result of note is that there is substantial persistence in the evolution of $e p r_{-} w$, as suggested by the coefficient on the lagged dependent variable (around 0.8). Interestingly, labor market policies and structural variables are also significant determinants of the evolution over time of women employment rates. In our preferred parsimonious specification reported in column (7), and obtained from imposing restrictions on the more general specification of column (6), both employment protection legislation and the number of children have a negative effect.

The $p$-value of the test of overidentifying restrictions is not suggestive of misspecification. However, the test of first order serial correlation suggests that the residuals (in difference) are white noise, which is consistent with the idiosyncratic shock in the equation in level being a random walk. If that were the case, lagged differences of predetermined or endogenous variables would not be legitimate instruments for the equation in levels and the use of the system estimator would be inappropriate in this case. For this reason, in columns (8) through (9) we present a set of results in which the difference estimator does not suffer from this problem. ${ }^{32}$ Column (8) contains the most general model. Column (9) retains the policy and structural variables that are more significant in the general model, while column (10) contains the same variables of column (7) for comparison and robustness.

The coefficient of women_cn remains significant, as it was in the Within estimates. Among the policy and structure variables, employment protection, the number of children, and now the size of the service sector, all display a significant negative coefficient. Summarizing, it appears that attitudes, some institutions (employment protection in particular), and some structural variables (number of children and size of the service sector) all play an important role in determining women employment rates. ${ }^{33}$ In assessing the quantitative implication of the model, one must now differentiate between impact and long run effects. However, the relative importance of the direct effect of attitudes and institutions does not depend on this choice. Using the long run multipliers, a change in our measure of attitudes from the first to the third quartile generates a change in women employment rates of 17.1 percentage points, while a similar change in employment protection legislation results in an increase of 18.6 percentage points. Both changes are large and lead us to conclude that both policies and culture matter. There is, therefore, at least the potential for policies to offset the effect of variation in attitudes. Whether the required changes in policies are feasible is an issue

\footnotetext{
${ }^{32}$ In estimating the differenced model, if the difference of the error term was serially uncorrelated, we could advance all lagged instruments by one period. We have tried this, but with no improvement in the results, so we have decided not to change the timing of the instruments. We have, however, excluded religious attitudes as an instrument because it contains no information about changes in attitude towards women work in the country of residence.

${ }^{33}$ Experiments in which we replaced the belief in God, as an instrument, with the degree of religious participation (measured by (at least) weekly attendance at religious services) yield similar results concerning the effects of culture, policies and structure. The only exception is that unemployment benefits are now positively and significantly associated with women employment rates, which is puzzling.
} 
we do not address in this paper.

As we have already discussed, culture could affect outcomes indirectly, through the effect it has on policies and institutions. For instance, societies characterized by a more traditional view of gender roles could set up policies and institutions to protect the male bread winner model through employment protection legislation that is likely to be more beneficial for primary workers in formal sectors, the majority of whom are likely to be men ${ }^{34}$. If this were the case our estimate of the effect of culture on women employment rates would capture only the direct effect of culture and would thus be downward biased.

In fact, if we look at the overall correlation coefficient between women_cn and epl, controlling for time dummies, it is (consistently with the discussion above) negative (-0.4) and significant at the $1 \%$ level, when we use current women_cn, and negative (-0.38) and significant at $5 \%$, when we use lagged women_cn. However, there is no information in the evolution over time of women_cn for the evolution in $e p l$ within countries (the correlation is not significantly different from zero, after introducing country fixed effects or running the regression in differences). All the correlation is cross sectional. ${ }^{35}$ Moreover, deeper attitudes or the attitudes of US immigrants do not matter in the first stage regression of $\mathrm{epl}$. Hence, there is no evidence of an indirect effect of changes in attitudes (or in their exogenous component) on women employment rates, through their effect on the evolution of labor market policies.

Next we turn to Table 8 where we repeat a similar exercise for the youth employment rate. Recall that there was no association between the attitude towards child independence and employment outcomes in the LSDV estimator. Instrumenting for youth_ $i$ using trust in the country of residence and of US immigrants as additional instruments, yields little support for the importance of attitudes towards child independence for youth employment rates. Even if we focus on the results obtained using the system estimator (columns (1) through (7)), in just one case (column (6)) youth_i displays a positive and significant coefficient. Policies do not appear to matter much either in the GMM estimates. Probably, the difficulty in finding adequate instruments does not allow us to pin down the effect of culture and policies on youth employment rates.

Finally in Table 9 we present the GMM estimates for the (log) hours of work. We report only the GMM system estimates because, the Arellano_Bond test of first-order serial correlation suggests that the idiosyncratic component of the error term is not serially correlated in the level equation (and hence is $M A(1)$ in the difference equation). ${ }^{36}$ The big difference relative to the Within estimates is that now the coefficient of holidays is negative and significant: considering holidays an important attribute of a job results in lower average hours of work. However, policies are also

\footnotetext{
${ }^{34}$ See Algan and Cahuc (2006) for a discussion of the effect of religious affiliation on employment protection.

${ }^{35}$ Alesina et al.(2009), using a larger set of countries, also find a positive cross sectional correlation between cultural attitudes (importance of family ties, both actual and inherited) and various measures of labor market regulation. Using micro data they also find a positive correlation between family ties and the desire for employment protection, whether or not one includes country fixed effects.

${ }^{36}$ For instance, in columns (6) and (7) the test suggests that we can reject the hypothesis that the difference of the error term is white noise at or close to the $5 \%$ level. The test of overidentifying restrictions is not indicative of misspecification.
} 
important. Contrary to the Within results, now the policy variables more robustly associated with hours of work are tax-wedge and ben. A wider tax wedge or more generous unemployment benefits lead to lower hours worked on average in a country. An increase in the wedge from the first to the third quartile results in a decrease in hours work of $6.2 \%$, while a similar increase in benefits results in a $1.8 \%$ drop. A change in attitudes towards generous holidays from the first to the third quartile leads to a $5.5 \%$ drop. These are sizeable effects, particularly those for tax-wedge and holidays (recall that the difference from the first to the third quartile of hours is $14.3 \%$ ). Union density is also significantly and negatively associated with average hours, which is what we would expect, given the push of unions in many countries to restrict hours of work. Finally, as for the within estimates, a higher fraction of women in the labor force is negatively associated with hours of work, while the association with the relative size of the service sector is positive. ${ }^{37}$ The bottom line is that in the case of hours worked too, both policies and attitudes matter.

Also in this case there is there is no evidence that contemporaneous or past changes in changes in attitudes (holidays) are correlated with changes in policies (tax-wedge and ben) However, in the first stage regression for $\Delta$ tax-wedge there is information in some of the cultural instruments. For instance, $\Delta$ tax-wedge is negatively and significantly associated at the $5 \%$ level with $\Delta$ imm_trust and positively and significantly associate at the $10 \%$ level with $\Delta$ imm_sex. In this case, an evolution in the exogenous component of cultural attitudes has both a direct and indirect effect on hours worked, the latter coming through its effect on taxes (there is no indirect effect, though, through the unemployment benefit variable). However, the thought experiment of changing, for instance, the tax wedge (or, more precisely, the component not related to culture) to offset the effect on hours worked of variations in attitudes, is still possible.

\section{Conclusions}

We have studied whether cultural attitudes towards work, gender and the young are a significant determinant of the evolution over time of the employment rates of women and of the young, and of hours worked in OECD countries. Beyond controlling for a larger menu of policies, institutions and other structural characteristics of the economy than has been done so far, our analysis improves upon existing studies of the role of "culture" on economic outcomes by dealing explicitly with the endogeneity of attitudes, policies and institutions, and by allowing for the persistent nature of labor market outcomes.

By using panel data on labor market outcomes, attitudes, policies and institutions, we were able to separate the time-invariant effect of these variables (which cannot be identified because it is captured by country fixed effects) from those effects that are associated with their time-varying components. We find that, even after instrumenting, allowing for persistence of outcomes and for an extensive menu of additional controls, culture still matters. More specifically, attitudes towards

\footnotetext{
${ }^{37}$ Experiments in which we replace the belief in God with the degree of religious participation give less sharp results on the effect of culture, probably because frequency of attendance at religious services is less informative about attitudes towards leisure than beliefs in God in the first stage regression.
} 
a woman's role in the family and towards leisure are statistically and economically important determinants of the employment rate of women and of average hours worked, respectively. However, we find that policies and other institutional or structural characteristics also matter. The results on the role of attitudes towards leisure, policies and institutions in determining the evolution over time of hours worked are new and particularly interesting in the light of the debate initiated by Prescott (2004) and Alesina, Glaeser and Sacerdote (2005).

In the case of women employment rates, the policy variable that is significant along with attitudes, is the OECD index of employment protection legislation. For hours worked the policy variables that play a role, along with attitudes, are the tax wedge and benefits. The quantitative impact of these policy variables (in particular, employment protection legislation and taxes) is large, so that changes in policies have at least the potential to undo the effect of variations in cultural traits on labor market outcomes.

We have used as instruments deeper attitudes in the country of residence and the attitudes of US immigrants, grouped by country of origin. Other instruments could be investigated in future work. For instance, following Giuliano (2007), the living arrangements of American immigrants could be used as an instrument for attitudes toward the young. Another interesting extension would require exploiting the variation over time in work attitudes and employment outcomes at the regional level in Europe. All this is on our research agenda for the future. 


\section{References}

[1] Aghion, P., Y. Algan and P. Cahuc (2008), "Can Policy Interact with Culture? Minimum Wage and the Quality of Labor Relations," NBER Working Paper No. 14327

[2] Alesina A., Y. Algan, P. Cahuc and P.Giuliano (2009), "Family Values and the Regulation of Labor," mimeo

[3] Alesina, A., E. Glaeser and B. Sacerdote(2001), "Why Doesn't the United States Have a European-Style Welfare State?,"Brookings Paper on Economics Activity, Fall 2001, 187-278

[4] Alesina, A., E. Glaeser and B. Sacerdote (2005), "Work and Leisure in the U.S. and Europe: Why So Different?," NBER Macroeconomic Annual 2005, 1-64

[5] Alesina A., and P.Giuliano (2007), "The Power of the Family," NBER Working Papers 13051, National Bureau of Economic Research, Inc.

[6] Alesina A., and P.Giuliano (2009), "Preferences for Redistribution," NBER Working Papers 14825, National Bureau of Economic Research, Inc.

[7] Alesina A., and E. Glaeser (2004), Fighting Poverty in the US and Europe: A World of Difference, Oxford University Press, Oxford UK.

[8] Alesina A., and E. La Ferrara (2002), "Who trusts others?," Journal of Public Economics, vol. 85(2), pages 207-234, August.

[9] Algan, Y., and P. Cahuc (2007), "The Roots of Low European Employment: Family Culture?," in Pissarides, C. and Frenkel, J. (eds.) NBER International Seminar on Macroeconomics 2005, MIT Press, 65-109.

[10] Algan, Y., and P. Cahuc (2006), "Job Protection: the Macho Hypothesis," Oxford Review of Economic Policy, vol. 22, n², Nov. 2006, 290-410

[11] Algan, Y., and P. Cahuc (2008), "Cultural Change and Economic Development," mimeo

[12] Antecol, H. (2000), "An Examination of Cross-Country Differences in the Gender Gap in Labor Force Participation Rates, Labour Economics, 7, pp. 409-426.

[13] Archimandrite, C. (1981), "Women in the Orthodox Church," Orthodox Life, Vol. 31, No. 1, pp. 34-41.

[14] Arellano, M., and S. Bond (1991), "Some Tests of Specification for Panel Data: Monte Carlo Evidence and an Application to Employment Equations," Review of Economic Studies 58: 277-297.

[15] Arellano, M., and O. Bover (1995), "Another Look at the Instrumental Variables Estimation of Error Components Models," Journal of Econometrics 68: 29-51.

[16] Barro, R., and R. McCleary (2003), "Religion and Economic Growth," NBER Working Paper No. W9682

[17] Barro, R., and J-W. Lee (2000), "International Data on Educational Attainment Updates and Implications," NBER Working Paper No. 7911, September 
[18] Bassanini A., and R. Duval (2006), "Employment Patterns in OECD Countries: Reassessing the Role of Policies and Institutions, "OECD Economics Department Working Papers No. 486.

[19] Bisin, A., and T. Verdier (2001), "The Economics of Cultural Transmission and the Evolution of Preferences," Journal of Economic Theory, 97(2), 298-319, 2001.

[20] Blundell, R., and S. Bond (1998), "Initial Conditions and Moment Restrictions in Dynamic Panel Data Models," Journal of Econometrics 87: 11-143.

[21] Blundell, R., and S. Bond (2000), "GMM Estimation with Persistent Panel Data: an Application to Production Functions," Econometric Reviews. Vol. 19, p.321-340

[22] Brugger, B., R. Lalive, and J. Zweimuller (2008), "Does Culture Affect Unemployment? Evidence from the Rostigraben," CEPR Discussion Paper N. 7405.

[23] Farré, L., and F. Vella, (2007), "The Intergenerational Transmission of Gender Role Attitudes and its Implications for Female Labor Force Participation," IZA Discussion Papers 2802, Institute for the Study of Labor.

[24] Fiori, G., G. Nicoletti, S. Scarpetta, and F. Schiantarelli (2008), "Employment Outcomes and the Interaction Between Product and Labor Market Deregulation: Are They Substitutes or Complements?," Boston College Working Paper 663.

[25] Fernàndez, R., A. Fogli and C. Olivetti (2004), "Mothers and Sons: Preference Formation and Female Labor Force Dynamics," Quarterly Journal of Economics 119: 1249-299.

[26] Fernàndez, R., and A. Fogli (2009), "Culture: An Empirical Investigation of Beliefs, Work and Fertility," American Economic Journal: Macroeconomics 1: 146-177.

[27] Fernàndez, R., and A. Fogli (2005b), "Fertility, the Role of Culture and Family Experience," NBER Working Paper No. 11569. Cambridge, MA: NBER.

[28] Fernàndez, R. (2006), "Culture and Economics," mimeo NYU.

[29] Fernàndez, R. (2007), "Women, Work and Culture," NBER Working Paper No. 12888. Cambridge, MA: NBER.

[30] Fernàndez, R. (2008), "Culture as Learning: The Evolution of Female Labor Force Participation over a Century," mimeo, NYU.

[31] Fogli, A., and L. Veldkamp, (2007), "Nature or Nurture? Learning and Female Labor Force Dynamics,". Federal Reserve Bank of Minneapolis. Staff Report 386.

[32] Fortin, N. (2005), "Gender Role Attitudes and Women's Labour Market Outcomes Across OECD countries, " Oxford Review of Economic Policy, Vol. 21, No. 3: 416-438.

[33] Fortin, N. (2008), "Gender Role Attitudes and Women's Labor Market Participation: The Persistent Appeal of Housewifery," mimeo, U. British Columbia.

[34] Giuliano, P. (2007), "Living Arrangements in Western Europe: Does Cultural Origin Matter?," Journal of the European Economic Association, 5(5): 927-952.

[35] Guiso, L., P. Sapienza and L. Zingales (2003), "People's Opium? Religion and Economic Attitudes," Journal of Monetary Economics 50: 225-282. 
[36] Guiso, L., P. Sapienza, and L. Zingales (2006), "Does Culture Affect Economic Outcomes?," Journal of Economic Perspectives, 2, Spring, 23-48.

[37] Inglehart, R. (1990), "Culture Shift," Princeton: Princeton University Press.

[38] Inglehart, R. (1997), "Modernization and Postmodernization: Cultural, Economic and Political Change in 43 Societies," Princeton: Princeton University Press.

[39] Licht, A., C. Goldschmidt, and S. H. Schwartz (2007), "Culture Rules: The Foundations of the Rule of Law and Other Norms of Governance," Journal of Comparative Economics 35: 659-688.

[40] Luperini, R., P. Castaldi, and L.Marchiani (2005), "La scrittura e l'interpretazione: storia e antologia della letteratura italiana nel quadro della civiltà europea," Palumbo, Palermo.

[41] Luttmer, E. (2001), "Group Loyalty and the Taste for Redistribution," Journal of Political Economy, vol. 109(3), pages 500-528, June.

[42] Nickell, S., L. Nunziata and W. Ochel (2005), "Unemployment in the OECD Since the 1960s: What Do We Know?," The Economic Journal, 115(500), January, 1-27.

[43] Prescott, E. (2004), "Why Do Americans Work so Much More than Europeans?," Quarterly Review, Federal Reserve Bank of Minneapolis, issue Jul, pages 2-13.

[44] Tabellini G. (2008a), "Institutions and Culture," Journal of the European Economic Association Papers and Proceedings, Vol.6(2-3)

[45] Tabellini G. (2008b), "Culture and Institutions: Economic Development in the Regions of Europe," forthcoming in Journal of the European Economic Association

[46] Weber, M. (1930), The Protestant Ethic and the Spirit of Capitalism, London, Allen \& Unwin. 


\section{A Data Appendix: sources and definitions}

\section{A.1 Employment and hours}

For most countries the employment and hours variables represent four year averages over the period 1981-1984, 1990-1993, 1999-2002. We will also use data for the 1972-1975 period in models with the lagged dependent variable. See Table A.1 for summary statistics on the main variables used in our econometric work.

epr_w Employment/Population ratio for Women.

Definition: Proportion of an economy's female population aged 25-54 that is employed. Source: OECD Labour Force Statistics. Updated in July 2008

Data adjustments: Austria: For the period 1990-1993 we used the observation in 1994 from OECD Labour Force Statistics. Belgium, Denmark: For the period 1972-1975 we used the E/P ratios estimates for women aged 25-54 years obtained using the following procedure. We started from the formula $\mathrm{E} / \mathrm{P}=(\mathrm{E} / \mathrm{LF})^{*}(\mathrm{LF} / \mathrm{P})$ where $\mathrm{P}$ is population of the relevant sex and age group, $\mathrm{LF}$ labor force, E employed in civilian employment and armed forced. We took the average LF/P, E and LF of women aged 15-64 between '72 and '75 and '81 and '84 from OECD Labor Force Statistics 1969-1989. We calculate the growth rate between these two periods and project backward our 1981-1984 figure for the employment/population ratio for women. Canada : For the period 19721975 we used the E/P ratios estimates for women aged 25-54 years obtained using the following procedure: we started from the formula $\mathrm{E} / \mathrm{P}=\mathrm{LF} / \mathrm{P}-\mathrm{U} / \mathrm{P}=\mathrm{LF} / \mathrm{P}-\mathrm{U} / \mathrm{LF} * \mathrm{LF} / \mathrm{P}$, where $\mathrm{P}$ is population of the relevant sex and age group, LF labor force and $\mathrm{U}$ unemployment, so that LF/P is the participation rate and $\mathrm{U} / \mathrm{LF}$ is the unemployment rate. We took the average $\mathrm{LF} / \mathrm{P}$ and U/LF of women aged 25-54 between '72 and '75 and '81 and '84 from OECD Labor Force Statistics 1969-1989. We calculated the growth rate between these two periods and projected backward our 1981-1984 figure for the employment/population ratio for women. Portugal : For the period 1972-1975 we used the average of the E/P ratios for women aged 25-54 years in 1974 and 1975. United-Kingdom: For the period 1981-1984 we used the observation in 1984 from OECD Labour Force Statistics. (Updated July 2008). For the period 1972-1975 we followed the same procedure explained for Canada.

epr_y Employment/Population ratio for Young.

Definition: Proportion of an economy's population aged 15-24 that is employed. Source: OECD Labour Force Statistics. Updated July 2008

Data adjustments: Austria: For the period 1972-1975 we used the E/P ratios estimates for youth aged 15-24 years for the Census years 1971. For the period 1981-1984 we used the E/P ratios estimates for youth aged 15-24 years for the Census years 1981. The estimates were derived using registered unemployment data by age and gender obtained from the OECD. For the period 1990-1993 we used the observation in 1994 from OECD Labour Force Statistics. (updated in July 2008).Belgium, Denmark: We followed the same procedure explained for $e p r_{-} w$, except that since the figures for men and women aged 15-24 were not available from OECD Labor Force Statistics, we had to apply the rate of growth of employment/population ratios of men and women aged 15-64. Canada: We followed the same procedure explained for epr $w$. Portugal : We followed the same procedure explained for epr_w. United-Kingdom: We followed the same procedure explained for epr_w.

hours Average annual hours actually worked per worker 
Definition: Total number of hours worked over the year divided by the average number of people in employment. Hours actually worked per person in employment are consistent with National Accounts concepts for Austria, Canada, Denmark, Finland, France, Germany, Italy, Korea, Norway, Spain, Sweden. Secretariat estimates for annual hours worked based on the European Labour Force Survey are used for Belgium, Ireland, the Netherlands and Portugal. The OECD warns that the data are intended for comparisons of trends over time and are unsuitable for comparisons of the level of average annual hours of work for a given year, because of differences in their sources, even within the first group of countries. Part-time workers are covered as well as full-time. Country specific notes can be found at: www.oecd.org/employment/outlook. Source: OECD Labour Force Statistics

\section{A.2 Attitudes in the country of residence}

List of countries with indication of the year of the survey for each available wave. Austria: 2nd wave 1990, 3rd wave 1999. Belgium: 1st 1981, 2nd 1990 , 3rd 1999. Canada: 1st 1982, 2nd 1990, 3rd 2000. Denmark: 1st 1981, 2nd 1990, 3rd 1999. Finland: 2nd 1990, 3rd 2000. France: 1st 1981, 2nd 1990, 3rd 1999. Germany: 1st 1981 (West Germany), 2nd 1990, 3rd 1999. Great Britain: 1st 1981 , 2nd 1990, 3rd 1999. Ireland: 1st 1981, 2nd 1990, 3rd 1999. Italy: 1st 1981, 2nd 1990, 3rd 1999. Japan 1st 1981, 2nd 1990, 3rd 2000. Netherlands: 1st 1981, 2nd 1990, 3rd 1999. Norway 1st 1982, 2nd 1990. Portugal: 2nd 1990, 3rd 1999. Spain: 1st 1981, 2nd 1990, 3rd 2000. Sweden: 1st 1982, 2nd 1990, 3rd 1999. United States: 1st 1982, 2nd: 1990, 3rd 1999. Note : women_cn is not available for Sweden 1st wave. women_jp is only available for 2 nd and 3rd wave.

women_cn The country/wave fixed effect in the probit model that uses "Do you think that a woman has to have children in order to be fulfilled or is this not necessary?" 0 denotes 'Necessary', 1 denotes 'Not Necessary' - See Table 1. Source: World and European Values Surveys (four waves integrated files: 1981-2004, v.20060423, 2006). The World Values Survey Association (www.worldvaluessurvey.org)and European Values Study Foundation (www.europeanvalues.nl).

women_jp The country/wave fixed effect in the probit model that uses "Do you agree or disagree with the following statements? When jobs are scarce men should have more right to a job than women?" 0 denotes agreement with the questions, 1 denotes disagreement - see Table 1. Source: World and European Values Surveys

youth_i The country/wave fixed effect in the probit model that uses "Here is a list of qualities that children can be encouraged to learn at home. Which if any do you consider to be especially important?Independence." 1 denotes independence being mentioned, 0 not mentioned See Table 1. Source: World and European Values Surveys

holidays The country/wave fixed effect in the probit model that uses "Here are some more aspects of a job that people say are important. Please look at them and tell me which ones you personally think are important in a job" 1 denotes generous holidays being mentioned, 0 not mentioned - See Table 1. Source: World and European Values Surveys

god The country/wave fixed effect in the probit model that uses "Which, if any, of the following do you believe in? God" Source: World and European Values Surveys

trust The country/wave fixed effect in the probit model that uses "Generally speaking, would you say that most people can be trusted or that you can't be too careful in dealing with 
people?" 1 denotes the answer "Most People can be trusted", 0 denotes "Can't be too careful" and "Don't know". Source: World and European Values Surveys

week The country/wave fixed effect in the probit model that uses "Apart from weddings, funerals and christenings, about how often do you attend religious services these days?" 1 denotes the answers 'More than once a week' and 'Once a week'; 0 denotes the other alternatives ('Once a month, 'Only on special holy days/Christmas/Easter days', 'Other specific holy days', 'Once a year', 'Less often', 'Never, practically never'). Source: World and European Values Surveys

\section{A.3 Attitudes of second (or higher) generation immigrants in US}

imm_fework The cluster/wave fixed effect in the probit model that uses "Do you approve or disapprove of a married woman earning money in business or industry if she has a husband capable of supporting her?" 1 denotes disagreement, 0 agreement. The probit model for the first wave is run over the period before 1985, for the second wave over the period 1986 -1993 and for the third wave over the period after 1994. The clusters are: 1.Irish (Ireland) 2. Japanese (Japan). 3.British (England \& Wales) 4.Canadian (French Canada-Other Canada) 5. German Speaking (Germany-Austria) 6.European Continental not German Speaking (Belgium, France, Netherlands) 7.Mediterranean (Italy, Spain, Portugal) 8.Nordic (Denmark, Finland, Norway, Sweden) Source: GENERAL SOCIAL SURVEYS.

imm_premarsx The cluster/wave fixed effect in the probit model that uses "There's been a lot of discussion about the way morals and attitudes about sex are changing in this country. If a man and woman have sex relations before marriage, do you think it is always wrong, almost always wrong, wrong only sometimes, or not wrong at all?" 1 denotes "wrong only sometimes, or not wrong at all", 0 "always wrong, almost always wrong". Periods for each wave and Clusters - see imm_fework. Source: GENERAL SOCIAL SURVEYS

imm_trust The cluster/wave fixed effect in the probit model that uses "Generally speaking, would you say that most people can be trusted or that you can't be too careful in dealing with people?" 1 denotes the answer "Most People can be trusted", 0 denotes "Can't be too careful" and "Don't know". Periods for each wave and Clusters - see imm_fework. Source: GENERAL SOCIAL SURVEYS

\section{A.4 Labour market policies}

ben Average unemployment benefit replacement rate

Definition: average unemployment benefit replacement rate across two income situations (100\% and $67 \%$ of APW earnings), three family situations (single, with dependent spouse, with spouse in work) and three different unemployment durations (1st year, 2nd and 3rd years, and 4th and 5th years of unemployment).Source: OECD, Benefits and Wages Database. Data adjustments: original data are available only for odd years. Data for even years are obtained by linear interpolation.

tax_wedge Tax wedge on labour use

Definition: share of personal income tax and all social security contributions (net of social benefits) to total labour cost (wages and employers' social security contributions) and averaged over two family types (single household and a couple with a dependent spouse and two children, both family types earning 100\% of an average worker income). Source: OECD, Taxing Wages. 
epl Employment Protection Legislation (epl)

Definition: OECD summary indicator of the stringency for Employment Protection Legislation for indefinite contract (regular) workers and fixed-term contract (temporary) workers, measured as a simple average of the index for indefinite and fixed-term contracts. Information on regular contracts include procedural inconveniences that employers face when trying to dismiss a worker; notice and several payments at different job tenures; and prevailing standards of and penalties for unfair dismissals. Information on fixed-term and temporary work agency contracts include: the objective reasons under which they can be offered; the maximum number of successive renewals; and the maximum cumulated duration of the contract.

\section{A.5 Labour market institutions}

udens Union density

Definition: trade union density rate, i.e. the share of workers affiliated to a trade union, in $\%$. Source: OECD, Employment Outlook 2004.

\section{A.6 Other variables}

\section{gap Output gap}

Definition: OECD measure of the gap between actual and potential output as a percentage of potential output. Source: OECD (2005) Economic Outlook 77.

serv_va Services, etc., value added (\% of GDP).

They include value added in wholesale and retail trade (including hotels and restaurants), transport, and government, financial, professional, and personal services such as education, health care, and real estate services. Also included are imputed bank service charges, import duties, and any statistical discrepancies noted by national compilers as well as discrepancies arising from rescaling. Source: World Development Indicators

edu_w Female education

Definition: number of years of education of female population aged 25 and over.

Source: Barro, R. J. and J-W. Lee (2000). Data adjustments as in Bassanini A., Duval R. (2006).

children Number of children per woman

Definition: ratio of total population aged 0-14 to female population aged 15-64.

Source: OECD, Annual Labour Force Statistics.

edu_y Relative youth education:

Definition: difference between the number of education years of total population aged 15 and over and the number of education years of total population aged 25 and over. Source: Barro, R. J. and J-W. Lee (2000). Data adjustments as in Bassanini A., Duval R. (2006).

pop65 Population ages 65 and above (\% of total).

Source: World Development Indicators

prot dummy variable, equal to 1 if the adherence fraction of population in 1900 for protestant religion is greater than that of any other religion , 0 otherwise. Source: Barro and McCleary (2003) 
cath dummy variable, equal to 1 if the adherence fraction of population in 1900 for catholic religion is greater than that of any other religion , 0 otherwise. Source: Barro and McCleary (2003)

oth_rel dummy variable, equal to 1 if the greatest adherence fraction of population in 1900 is not for protestant religion, nor for catholic religion , 0 otherwise. Source: Barro and McCleary (2003) 

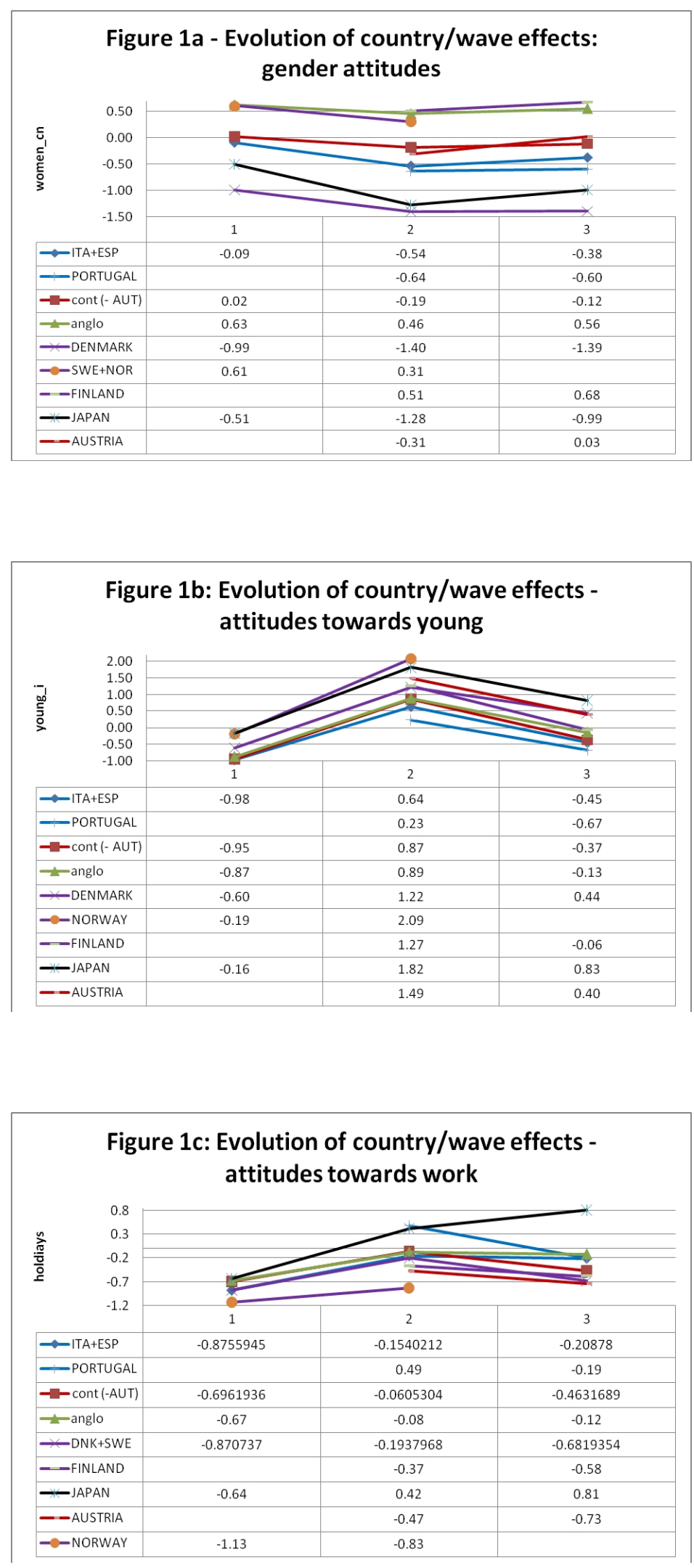

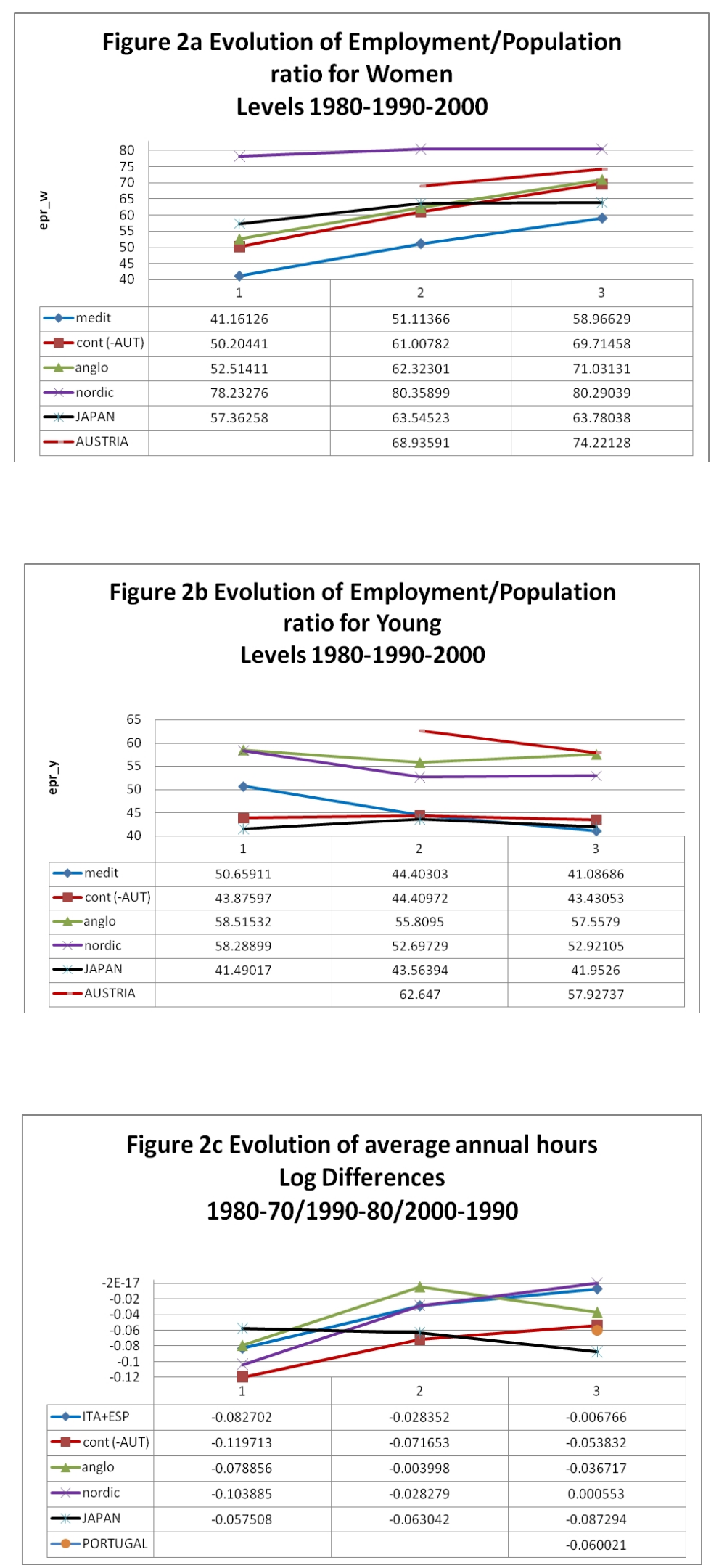
Table 1: Estimations of Family and Work Attitudes : Probit Estimates for 2000 Wave

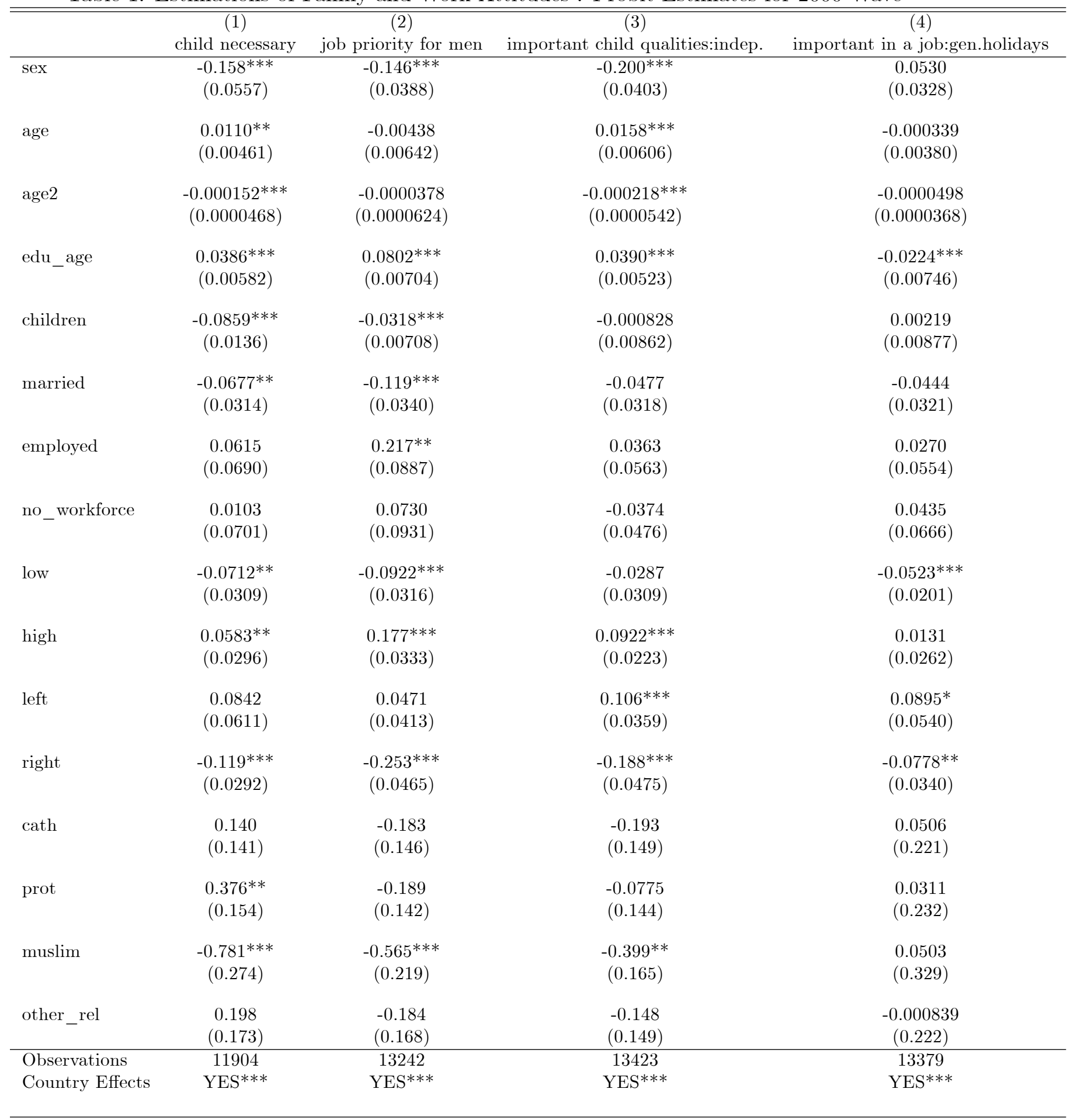

Clustered errors in parentheses(allowing for arbitrary correlations within countries) ${ }^{*} p<0.10,{ }^{* *} p<0.05, * * * p<0.01$

Omitted Categories : Unemployed, Medium Income, Pol.Views:Center, No Religion. In columns 1 and 2, 0 denotes agreement with the questions 1 denotes disagreement. In column 3, 1 denotes independence being mentioned; 0 not mentioned In column 4, 1 denotes generous holidays being mentioned; 0 not mentioned 
Table 2: Family and Work Attitudes and Employment Rates for Women: (using women_cn): Within Estimates

\begin{tabular}{|c|c|c|c|c|c|c|}
\hline & $\begin{array}{c}(1) \\
\text { epr_w }\end{array}$ & $\begin{array}{c}(2) \\
\text { epr_w }\end{array}$ & $\begin{array}{c}(3) \\
\text { epr_w }\end{array}$ & $\begin{array}{c}(4) \\
\text { epr_w }\end{array}$ & $\begin{array}{c}(5) \\
\text { epr_w }\end{array}$ & $\begin{array}{l}(6) \\
\text { epr_w }\end{array}$ \\
\hline women_cn & $\begin{array}{c}11.97 * * * \\
(4.437)\end{array}$ & $\begin{array}{c}9.096^{* *} \\
(4.351)\end{array}$ & $\begin{array}{l}7.989 * * \\
(3.680)\end{array}$ & $\begin{array}{c}10.48^{* * *} \\
(3.655)\end{array}$ & $\begin{array}{l}7.529 * * \\
(2.947)\end{array}$ & $\begin{array}{l}5.066^{*} \\
(3.063)\end{array}$ \\
\hline gap & & $\begin{array}{c}0.827^{* *} \\
(0.345)\end{array}$ & $\begin{array}{c}0.385 \\
(0.362)\end{array}$ & $\begin{array}{c}0.675 * * \\
(0.285)\end{array}$ & $\begin{array}{l}0.466^{*} \\
(0.273)\end{array}$ & $\begin{array}{l}0.457^{*} \\
(0.269)\end{array}$ \\
\hline children & & & $\begin{array}{c}-56.66^{* * *} \\
(12.60)\end{array}$ & & $\begin{array}{c}-53.90^{* * *} \\
(13.30)\end{array}$ & $\begin{array}{l}-49.65^{* * *} \\
(8.435)\end{array}$ \\
\hline serv_va & & & $\begin{array}{c}0.704^{* *} \\
(0.308)\end{array}$ & & $\begin{array}{c}0.396 \\
(0.282)\end{array}$ & \\
\hline pop65 & & & $\begin{array}{c}-1.602^{* *} \\
(0.624)\end{array}$ & & $\begin{array}{c}-1.151^{* *} \\
(0.583)\end{array}$ & $\begin{array}{c}-0.979^{* *} \\
(0.489)\end{array}$ \\
\hline edu_w & & & $\begin{array}{c}-1.902 \\
(1.543)\end{array}$ & & $\begin{array}{c}-0.986 \\
(1.473)\end{array}$ & \\
\hline epl & & & & $\begin{array}{c}-7.448^{* * *} \\
(2.127)\end{array}$ & $\begin{array}{c}-7.585^{* * *} \\
(1.717)\end{array}$ & $\begin{array}{l}-5.803^{* * *} \\
(1.670)\end{array}$ \\
\hline udens & & & & $\begin{array}{c}-0.442^{* * *} \\
(0.127)\end{array}$ & $\begin{array}{l}-0.182 \\
(0.134)\end{array}$ & \\
\hline ben & & & & $\begin{array}{c}-0.353^{* *} \\
(0.158)\end{array}$ & $\begin{array}{c}-0.123 \\
(0.152)\end{array}$ & \\
\hline tax_wedge & & & & $\begin{array}{c}-0.412 \\
(0.280)\end{array}$ & $\begin{array}{c}-0.759^{* * *} \\
(0.255)\end{array}$ & $\begin{array}{l}-1.056^{* * *} \\
(0.215)\end{array}$ \\
\hline Observations & 46 & 46 & 46 & 46 & 46 & 46 \\
\hline Countries & 17 & 17 & 17 & 17 & 17 & 17 \\
\hline
\end{tabular}

Standard errors in parentheses

${ }^{*} p<0.10,{ }^{* *} p<0.05,{ }^{* * *} p<0.01$

Period Effects and Country Effects are entered in every column

women_cn is the country/wave fixed effect in the probit model that uses: -Do you think that a woman has to have children in order to be fulfilled or is this not necessary?

1 means 'not necessary', 0 'needs children' - See Table 1 
Table 3: Family and Work Attitudes and Employment Rates for Women (using women_jp): Within Estimates

\begin{tabular}{|c|c|c|c|c|c|c|}
\hline & $\begin{array}{c}(1) \\
\text { epr_w }\end{array}$ & $\begin{array}{c}(2) \\
\text { epr_w }\end{array}$ & $\begin{array}{c}(3) \\
\text { epr_w }\end{array}$ & $\begin{array}{c}(4) \\
\text { epr_w }\end{array}$ & $\begin{array}{c}(5) \\
\text { epr_w }\end{array}$ & $\begin{array}{l}(6) \\
\text { epr_w }\end{array}$ \\
\hline women_jp & $\begin{array}{c}59.43^{* * *} \\
(16.96)\end{array}$ & $\begin{array}{c}58.20^{* * *} \\
(17.27)\end{array}$ & $\begin{array}{l}31.34^{*} \\
(16.18)\end{array}$ & $\begin{array}{c}37.94^{* * *} \\
(13.19)\end{array}$ & $\begin{array}{c}26.13^{* * *} \\
(7.830)\end{array}$ & $\begin{array}{l}28.52^{* * *} \\
(7.868)\end{array}$ \\
\hline gap & & $\begin{array}{c}0.132 \\
(0.367)\end{array}$ & $\begin{array}{c}-0.0598 \\
(0.638)\end{array}$ & $\begin{array}{c}0.296 \\
(0.257)\end{array}$ & $\begin{array}{c}-1.160^{* * *} \\
(0.373)\end{array}$ & $\begin{array}{l}-0.848^{* * *} \\
(0.307)\end{array}$ \\
\hline children & & & $\begin{array}{c}-68.16^{* * *} \\
(17.29)\end{array}$ & & $\begin{array}{c}-87.41^{* * *} \\
(13.03)\end{array}$ & $\begin{array}{l}-73.32^{* * *} \\
(8.559)\end{array}$ \\
\hline serv_va & & & $\begin{array}{c}0.329 \\
(0.489)\end{array}$ & & $\begin{array}{c}-0.559^{* *} \\
(0.245)\end{array}$ & $\begin{array}{c}-0.546^{* *} \\
(0.252)\end{array}$ \\
\hline pop65 & & & $\begin{array}{c}-0.871 \\
(0.982)\end{array}$ & & $\begin{array}{c}-2.200^{* * *} \\
(0.706)\end{array}$ & $\begin{array}{l}-1.451^{* * *} \\
(0.476)\end{array}$ \\
\hline edu_w & & & $\begin{array}{c}-5.546^{* *} \\
(2.331)\end{array}$ & & $\begin{array}{c}-5.700^{* * *} \\
(1.157)\end{array}$ & $\begin{array}{l}-5.535^{* * *} \\
(1.185)\end{array}$ \\
\hline epl & & & & $\begin{array}{l}-1.469 \\
(1.648)\end{array}$ & $\begin{array}{c}-2.479 * * * \\
(0.921)\end{array}$ & $\begin{array}{l}-2.861^{* * *} \\
(0.906)\end{array}$ \\
\hline udens & & & & $\begin{array}{c}-0.525^{* * *} \\
(0.179)\end{array}$ & $\begin{array}{c}0.213 \\
(0.152)\end{array}$ & \\
\hline ben & & & & $\begin{array}{c}0.155 \\
(0.133)\end{array}$ & $\begin{array}{c}0.270^{* * *} \\
(0.0878)\end{array}$ & $\begin{array}{l}0.211^{* * *} \\
(0.0793)\end{array}$ \\
\hline tax_wedge & & & & $\begin{array}{c}-1.490^{* * *} \\
(0.278)\end{array}$ & $\begin{array}{c}-1.592^{* * *} \\
(0.156)\end{array}$ & $\begin{array}{l}-1.562^{* * *} \\
(0.159)\end{array}$ \\
\hline Observations & 33 & 33 & 33 & 33 & 33 & 33 \\
\hline Countries & 17 & 17 & 17 & 17 & 17 & 17 \\
\hline
\end{tabular}

Standard errors in parentheses

${ }^{*} p<0.10,{ }^{* *} p<0.05,{ }^{* * *} p<0.01$

Period Effects and Country Effects are entered in every column

women jp is the country/wave fixed effect in the probit model that uses: -Do you agree or disagree with the following statements? When jobs are scarce, men should have more right to a job than women 0 denotes agreement 1 disagreement - See Table 1 
Table 4: Family and Work Attitudes and Employment Rates for Youth: Within Estimates

\begin{tabular}{|c|c|c|c|c|c|c|}
\hline & $\begin{array}{c}(1) \\
\text { epr_y }\end{array}$ & $\begin{array}{c}(2) \\
\text { epr_y }\end{array}$ & $\begin{array}{c}(3) \\
\text { epr_y }\end{array}$ & $\begin{array}{c}(4) \\
\text { epr_y }\end{array}$ & $\begin{array}{c}(5) \\
\text { epr_y }\end{array}$ & $\begin{array}{l}(6) \\
\text { epr_y }\end{array}$ \\
\hline youth_i & $\begin{array}{c}-9.984^{* *} \\
(5.015)\end{array}$ & $\begin{array}{l}-6.125 \\
(4.489)\end{array}$ & $\begin{array}{l}-5.047 \\
(4.668)\end{array}$ & $\begin{array}{l}-4.527 \\
(3.566)\end{array}$ & $\begin{array}{l}-5.172 \\
(3.589)\end{array}$ & $\begin{array}{l}-3.758 \\
(3.562)\end{array}$ \\
\hline gap & & $\begin{array}{c}1.469 * * * \\
(0.382)\end{array}$ & $\begin{array}{c}1.608^{* * *} \\
(0.432)\end{array}$ & $\begin{array}{c}1.579 * * * \\
(0.320)\end{array}$ & $\begin{array}{c}1.357^{* * *} * \\
(0.367)\end{array}$ & $\begin{array}{l}1.488^{* * *} \\
(0.314)\end{array}$ \\
\hline serv_va & & & $\begin{array}{c}0.245 \\
(0.376)\end{array}$ & & $\begin{array}{c}-0.295 \\
(0.310)\end{array}$ & \\
\hline edu_y & & & $\begin{array}{l}-2.734 \\
(4.312)\end{array}$ & & $\begin{array}{c}-6.849^{*} \\
(3.544)\end{array}$ & $\begin{array}{c}-5.893^{*} \\
(3.457)\end{array}$ \\
\hline epl & & & & $\begin{array}{c}-3.441^{*} \\
(2.053)\end{array}$ & $\begin{array}{l}-3.230 \\
(1.975)\end{array}$ & \\
\hline udens & & & & $\begin{array}{c}-0.0606 \\
(0.140)\end{array}$ & $\begin{array}{l}-0.149 \\
(0.141)\end{array}$ & \\
\hline ben & & & & $\begin{array}{c}0.362^{* *} \\
(0.156)\end{array}$ & $\begin{array}{c}0.339 * * \\
(0.150)\end{array}$ & $\begin{array}{l}0.392^{* * *} \\
(0.151)\end{array}$ \\
\hline tax_wedge & & & & $\begin{array}{c}-1.487^{* * *} \\
(0.290)\end{array}$ & $\begin{array}{c}-1.629 * * * \\
(0.294)\end{array}$ & $\begin{array}{l}-1.546^{* * *} \\
(0.287)\end{array}$ \\
\hline Observations & 47 & 47 & 47 & 47 & 47 & 47 \\
\hline Countries & 17 & 17 & 17 & 17 & 17 & 17 \\
\hline
\end{tabular}

Standard errors in parentheses

${ }^{*} p<0.10,{ }^{* *} p<0.05, * * * p<0.01$

Period Effects and Country Effects are entered in every column

youth_ $\mathrm{i}$ is the country/wave fixed effect in the probit model that uses: -Here is a list of qualities

that children can be encouraged to learn at home. Which if any do you consider to be especially important?

1 denotes independence being mentioned, 0 not mentioned - See Table 1 
Table 5: Family and Work Attitudes and Log Average Annual Hours: Within Estimates

\begin{tabular}{|c|c|c|c|c|c|c|}
\hline & $\begin{array}{c}(1) \\
\text { hours }\end{array}$ & $\begin{array}{c}(2) \\
\text { hours }\end{array}$ & $\begin{array}{c}(3) \\
\text { hours }\end{array}$ & $\begin{array}{c}(4) \\
\text { hours }\end{array}$ & $\begin{array}{c}(5) \\
\text { hours }\end{array}$ & $\begin{array}{c}(6) \\
\text { hours }\end{array}$ \\
\hline holidays & $\begin{array}{l}-0.0190 \\
(0.0225)\end{array}$ & $\begin{array}{c}-0.0182 \\
(0.0222)\end{array}$ & $\begin{array}{c}-0.0236 \\
(0.0193)\end{array}$ & $\begin{array}{c}-0.000561 \\
(0.0207)\end{array}$ & $\begin{array}{c}-0.00613 \\
(0.0177)\end{array}$ & $\begin{array}{c}-0.0148 \\
(0.0174)\end{array}$ \\
\hline gap & & $\begin{array}{c}0.00347 \\
(0.00300)\end{array}$ & $\begin{array}{c}0.00758^{* *} \\
(0.00305)\end{array}$ & $\begin{array}{c}0.00664^{* *} \\
(0.00296)\end{array}$ & $\begin{array}{c}0.0113^{* * *} \\
(0.00294)\end{array}$ & $\begin{array}{c}0.0110^{* * *} \\
(0.00288)\end{array}$ \\
\hline serv_va & & & $\begin{array}{c}0.00260 \\
(0.00246)\end{array}$ & & $\begin{array}{l}0.00382^{*} \\
(0.00227)\end{array}$ & $\begin{array}{c}0.00432^{*} \\
(0.00224)\end{array}$ \\
\hline epr_w & & & $\begin{array}{c}-0.00363^{* * *} \\
(0.000967)\end{array}$ & & $\begin{array}{c}-0.00332^{* * *} \\
(0.000946)\end{array}$ & $\begin{array}{c}-0.00325^{* * *} \\
(0.000866)\end{array}$ \\
\hline epl & & & & $\begin{array}{c}-0.0458 * * \\
(0.0184)\end{array}$ & $\begin{array}{c}-0.0522^{* * *} \\
(0.0158)\end{array}$ & $\begin{array}{c}-0.0527^{* * *} \\
(0.0154)\end{array}$ \\
\hline udens & & & & $\begin{array}{l}0.00222^{*} \\
(0.00121)\end{array}$ & $\begin{array}{c}0.00121 \\
(0.00108)\end{array}$ & \\
\hline ben & & & & $\begin{array}{c}0.000376 \\
(0.00137)\end{array}$ & $\begin{array}{l}0.000453 \\
(0.00117)\end{array}$ & \\
\hline tax_wedge & & & & $\begin{array}{c}-0.00149 \\
(0.00293) \\
\end{array}$ & $\begin{array}{c}-0.00321 \\
(0.00267) \\
\end{array}$ & \\
\hline Observations & 44 & 44 & 44 & 44 & 44 & 44 \\
\hline Countries & 16 & 16 & 16 & 16 & 16 & 16 \\
\hline
\end{tabular}

Standard errors in parentheses

${ }^{*} p<0.10,{ }^{* *} p<0.05,{ }^{* * *} p<0.01$

Period Effects and Country Effects are entered in every column

holidays is the country/wave fixed effect in the probit model that uses: -Here are some

more aspects of a job that people say are important.Please

look at them and tell me which ones you personally think are important in a job

1 denotes generous holidays being mentioned, 0 not mentioned - see Table 1 
Table 6: Relevance of Instuments for Attitudes

\section{DEEP ATTITUDES}

\begin{tabular}{|c|c|c|c|c|}
\hline 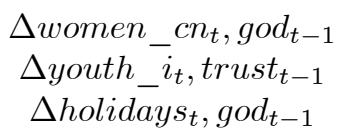 & $\begin{array}{l}\mathrm{F}=1.33 \\
\mathrm{r}=.161 \\
\mathrm{~F}=5.39\end{array}$ & $\begin{array}{l}(.287) \\
(.395) \\
(.006)\end{array}$ & $\begin{array}{c}\text { women_cn }_{t}, \Delta \text { god }_{t} \\
\text { youth_i }_{t}, \Delta \text { trust }_{t} \\
\text { holidays }_{t}, \Delta \text { god }_{t}\end{array}$ & $\begin{array}{c}\mathrm{F}=6.57 \\
\mathrm{r}=.387 \\
\mathrm{~F}=105.76\end{array}$ \\
\hline
\end{tabular}

US IMMIGRANTS ATTITUDES

\begin{tabular}{|c|c|c|c|c|c|}
\hline$\Delta w o m e n_{-} c n_{t}, \Delta i m m \_$fework $k_{t}$ & $\mathrm{r}=.408$ & $(.035)$ & women_cn $_{t}, \Delta i m m \_$fework $k_{t}$ & $\mathrm{r}=.014$ & $(.941)$ \\
\hline$\Delta$ women_cn, , $\Delta i m m \_p r e m a r s x_{t}$ & $\mathrm{r}=.423$ & $(.028)$ & women_cn,$\Delta i m m \_p r e m a r s x_{t}$ & $\mathrm{r}=.22$ & $(.242)$ \\
\hline$\Delta y o u \bar{n} g \_i_{t}, \Delta i m m \_$trust $_{t}$ & $\mathrm{r}=-.146$ & $(.460)$ & youth_i $i_{t}, \Delta$ imm_trust ${ }_{t}$ & $\mathrm{r}=-.34$ & $061)$ \\
\hline$\Delta$ holidays $_{t}, \Delta$ imm_trust $_{t}$ & $\mathrm{r}=-.0384$ & $(.048)$ & holidays $_{t}, \Delta i m m \_$trust $_{t}$ & $\mathrm{r}=-.345$ & $.067)$ \\
\hline$\Delta$ holidays $_{t}, \Delta i m m \_$premarsx $x_{t}$ & $\mathrm{r}=-.376$ & $(.053)$ & holidays $_{t}, \Delta i m m \_$premarsx $x_{t}$ & $r=-.367$ & $(.050)$ \\
\hline
\end{tabular}

1st-STAGES REGRESSIONS

\begin{tabular}{ccccc} 
& diff eq. & \multicolumn{2}{c}{ level eq. } \\
women_cn & $\mathrm{F}=6.74$ & $(.002)$ & & $\mathrm{F}=15.40$ \\
youth_i $i$ & $\mathrm{~F}=1.04$ & $(.367)$ & $\mathrm{F}=11.45$ &.$(000)$ \\
holidays & $\mathrm{F}=8.80$ & $(.001)$ & $\mathrm{F}=54.30$ &.$(000)$
\end{tabular}

r denotes the correlation coefficient. F denotes the F-Test of significance of the instruments.

Marginal probabilities in parentheses.

god denotes the interaction of beliefs in God with the historically dominant religious affiliation of the country(prot, cath, other)

Time dummies always included.

Each first-stage regression refers to the specification containing only the attitudinal variable and the lagged outcome 
Table 7: GMM Estimates for Women Employemt Rates

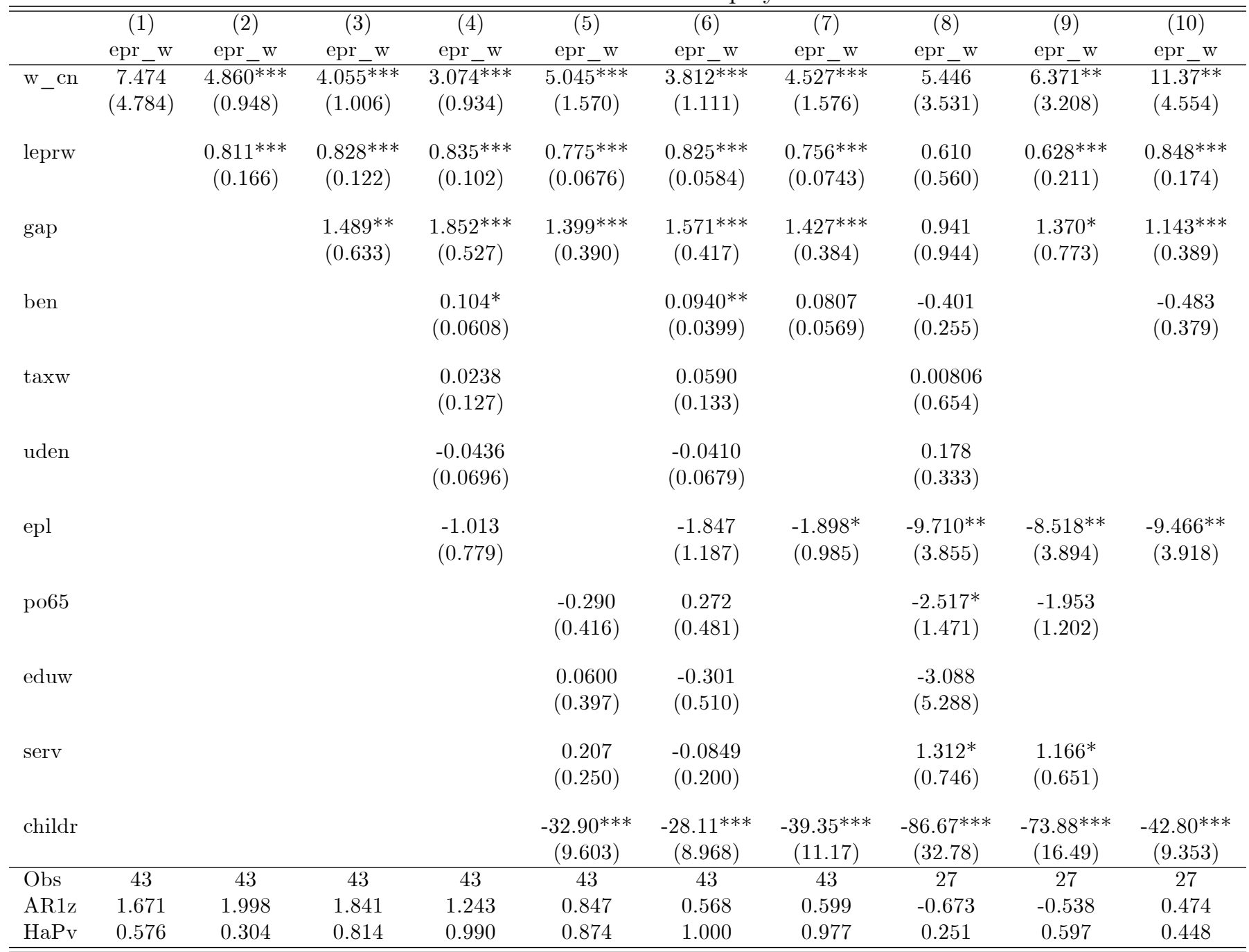

Standard errors in parentheses

* $p<0.10,{ }^{* *} p<0.05, * * * p<0.01$

Period Effects are entered in every columns

Columns 1 to 7 report the system estimator results using religious beliefs of the country of residence

(treated as predeterminate) and attitudes towards female work and sex of American immigrants

(treated as exogenous) as additional instruments.

Columns 8 to 10 report the difference estimator results using attitudes towards female work

and sex of American immigrants as additional instruments

In all equations appropriately legged included variables are used as instruments.

gap, ben, serv_va, children treated as endogenous, pop65 as exogenous. edu_w, tax_wed, udens and epl as prederminate

For all variables only the shortest allowable lag is used as instrument. 
Table 8: GMM Estimates for Youth Employemt Rates

\begin{tabular}{|c|c|c|c|c|c|c|c|c|c|}
\hline & $\begin{array}{c}(1) \\
\text { epr_y }\end{array}$ & $\begin{array}{c}(2) \\
\text { epr_y }\end{array}$ & $\begin{array}{c}(3) \\
\text { epr_y }\end{array}$ & $\begin{array}{c}(4) \\
\text { epr_y }\end{array}$ & $\begin{array}{c}5) \\
\text { epr_y }\end{array}$ & $\begin{array}{c}(6) \\
\text { epr_y }\end{array}$ & $\begin{array}{c}(7) \\
\text { epr_y }\end{array}$ & $\begin{array}{c}(8) \\
\text { epr_y }\end{array}$ & $\begin{array}{c}(9) \\
\text { epr_y }\end{array}$ \\
\hline youth_i & $\begin{array}{l}11.76^{* *} \\
(5.471)\end{array}$ & $\begin{array}{c}5.915 \\
(3.830)\end{array}$ & $\begin{array}{c}4.798 \\
(3.214)\end{array}$ & $\begin{array}{c}4.870 \\
(3.795)\end{array}$ & $\begin{array}{c}5.824 \\
(3.905)\end{array}$ & $\begin{array}{c}5.065 \\
(4.601)\end{array}$ & $\begin{array}{c}6.938^{* * *} \\
(2.534)\end{array}$ & $\begin{array}{l}-8.000 \\
(7.186)\end{array}$ & $\begin{array}{l}-13.81 \\
(13.19)\end{array}$ \\
\hline l_epr_y & & $\begin{array}{c}0.621^{* * *} \\
(0.157)\end{array}$ & $\begin{array}{c}0.715^{* * *} \\
(0.0896)\end{array}$ & $\begin{array}{c}0.623^{* * *} \\
(0.142)\end{array}$ & $\begin{array}{c}0.649^{* * *} \\
(0.131)\end{array}$ & $\begin{array}{c}0.655^{* * *} \\
(0.170)\end{array}$ & $\begin{array}{c}0.627^{* * *} \\
(0.117)\end{array}$ & $\begin{array}{c}0.317 \\
(0.219)\end{array}$ & $\begin{array}{c}0.138 \\
(0.241)\end{array}$ \\
\hline gap & & & $\begin{array}{c}0.386 \\
(1.004)\end{array}$ & $\begin{array}{c}1.802^{* * *} \\
(0.556)\end{array}$ & $\begin{array}{c}1.299 \\
(1.051)\end{array}$ & $\begin{array}{c}2.735^{* * *} \\
(0.898)\end{array}$ & $\begin{array}{c}2.134 \\
(1.422)\end{array}$ & $\begin{array}{c}1.638 \\
(1.212)\end{array}$ & $\begin{array}{c}3.175 \\
(1.982)\end{array}$ \\
\hline ben & & & & $\begin{array}{l}0.494^{*} \\
(0.266)\end{array}$ & & $\begin{array}{c}-0.0269 \\
(0.310)\end{array}$ & & $\begin{array}{c}0.101 \\
(0.863)\end{array}$ & \\
\hline tax_wedge & & & & $\begin{array}{l}-0.160 \\
(0.572)\end{array}$ & & $\begin{array}{c}0.245 \\
(0.535)\end{array}$ & & $\begin{array}{c}-0.446 \\
(1.164)\end{array}$ & \\
\hline udens & & & & $\begin{array}{c}0.00823 \\
(0.177)\end{array}$ & & $\begin{array}{c}-0.0556 \\
(0.120)\end{array}$ & & $\begin{array}{c}-0.530 \\
(0.870)\end{array}$ & \\
\hline epl & & & & $\begin{array}{l}-2.775 \\
(2.566)\end{array}$ & & $\begin{array}{c}-3.438^{* *} \\
(1.708)\end{array}$ & $\begin{array}{l}-2.417 \\
(1.993)\end{array}$ & $\begin{array}{c}-3.423 \\
(7.928)\end{array}$ & $\begin{array}{l}-1.899 \\
(5.282)\end{array}$ \\
\hline edu_y & & & & & $\begin{array}{l}-0.830 \\
(3.549)\end{array}$ & $\begin{array}{l}-1.955 \\
(5.911)\end{array}$ & & $\begin{array}{c}-11.20 \\
(17.83)\end{array}$ & \\
\hline serv_va & & & & & $\begin{array}{c}1.064 \\
(0.799)\end{array}$ & $\begin{array}{c}1.639^{* *} \\
(0.768)\end{array}$ & $\begin{array}{c}1.372^{* *} \\
(0.611)\end{array}$ & $\begin{array}{c}0.139 \\
(1.434)\end{array}$ & $\begin{array}{c}1.382 \\
(2.417)\end{array}$ \\
\hline Obs & 44 & 44 & 44 & 44 & 44 & 44 & 44 & 28 & 28 \\
\hline $\mathrm{AR}(1) \mathrm{z}-\mathrm{st}$ & 0.589 & -0.772 & -1.368 & -1.144 & -2.004 & -1.140 & -1.578 & -0.601 & 0.150 \\
\hline HansenPv & 0.327 & 0.607 & 0.162 & 0.765 & 0.550 & 1.000 & 0.565 & 0.556 & 0.775 \\
\hline
\end{tabular}

Standard errors in parentheses

${ }^{*} p<0.10,{ }^{* *} p<0.05,{ }^{* * *} p<0.01$

Period Effects are entered in every columns

Columns 1 to 7 report the system estimator results using attitudes towards trust of the country of residence (treated as predeterminate) and attitudes towards trust of American immigrants (treated as exogenous) as additional instruments. Columns 8 and 9 report the difference estimator results using attitudes towards trust of American immigrants as additional instruments.

In all equations appropriately legged included variables are used as instruments.

gap, ben, serv_va treated as endogenous, edu_y, tax_wed, udens and epl as prederminate

For all variables only the shortest allowable lag is used as instrument. 
Table 9: GMM System Estimates for Log Average Annual Hours

\begin{tabular}{|c|c|c|c|c|c|c|c|}
\hline & $\begin{array}{c}(1) \\
\text { hours }\end{array}$ & $\begin{array}{c}(2) \\
\text { hours }\end{array}$ & $\begin{array}{c}(3) \\
\text { hours }\end{array}$ & $\begin{array}{c}(4) \\
\text { hours }\end{array}$ & $\begin{array}{c}(5) \\
\text { hours }\end{array}$ & $\begin{array}{c}(6) \\
\text { hours }\end{array}$ & $\begin{array}{c}(7) \\
\text { hours }\end{array}$ \\
\hline holidays & $\begin{array}{l}0.0997^{* *} \\
(0.0444)\end{array}$ & $\begin{array}{c}-0.0524^{* * *} \\
(0.0187)\end{array}$ & $\begin{array}{c}-0.0511^{* * *} \\
(0.0177)\end{array}$ & $\begin{array}{l}-0.0425^{*} \\
(0.0217)\end{array}$ & $\begin{array}{c}-0.0813^{* * *} \\
(0.0292)\end{array}$ & $\begin{array}{c}-0.0781^{* * *} \\
(0.0220)\end{array}$ & $\begin{array}{c}-0.0840 * * * \\
(0.0203)\end{array}$ \\
\hline 1_hours & & $\begin{array}{c}0.990^{* * * *} \\
(0.110)\end{array}$ & $\begin{array}{c}0.972^{* * * *} \\
(0.107)\end{array}$ & $\begin{array}{c}0.963^{* * * *} \\
(0.134)\end{array}$ & $\begin{array}{c}0.839 * * * \\
(0.0835)\end{array}$ & $\begin{array}{c}0.950 * * * \\
(0.0786)\end{array}$ & $\begin{array}{c}0.914^{* * *} \\
(0.101)\end{array}$ \\
\hline gap & & & $\begin{array}{l}-0.00151 \\
(0.00433)\end{array}$ & $\begin{array}{l}-0.00249 \\
(0.00438)\end{array}$ & $\begin{array}{l}-0.00296 \\
(0.00336)\end{array}$ & $\begin{array}{l}0.000838 \\
(0.00234)\end{array}$ & $\begin{array}{l}-0.000574 \\
(0.00254)\end{array}$ \\
\hline serv_va & & & & $\begin{array}{l}0.000433 \\
(0.00295)\end{array}$ & & $\begin{array}{c}0.00571^{* * *} \\
(0.00178)\end{array}$ & $\begin{array}{c}0.00468^{* *} \\
(0.00224)\end{array}$ \\
\hline epr_w & & & & $\begin{array}{c}0.000483 \\
(0.000785)\end{array}$ & & $\begin{array}{c}-0.00125^{* *} \\
(0.000492)\end{array}$ & $\begin{array}{c}-0.00135^{* * *} \\
(0.000474)\end{array}$ \\
\hline tax_wedge & & & & & $\begin{array}{c}-0.00389 * * * \\
(0.00127)\end{array}$ & $\begin{array}{c}-0.00382^{* * *} \\
(0.00131)\end{array}$ & $\begin{array}{c}-0.00422^{* * *} \\
(0.00111)\end{array}$ \\
\hline epl & & & & & $\begin{array}{c}0.00792 \\
(0.00680)\end{array}$ & $\begin{array}{l}-0.00305 \\
(0.00552)\end{array}$ & \\
\hline udens & & & & & $\begin{array}{c}0.00141^{* * *} \\
(0.000387)\end{array}$ & $\begin{array}{c}0.00186^{* * *} \\
(0.000438)\end{array}$ & $\begin{array}{c}0.00195^{* * *} \\
(0.000408)\end{array}$ \\
\hline ben & & & & & $\begin{array}{c}-0.00120^{* *} \\
(0.000514)\end{array}$ & $\begin{array}{c}-0.000904^{*} \\
(0.000468)\end{array}$ & $\begin{array}{c}-0.00106^{* *} \\
(0.000506)\end{array}$ \\
\hline Observations & 41 & 36 & 36 & 36 & 36 & 36 & 36 \\
\hline $\mathrm{AR}(1) \mathrm{z}$-stat & 0.780 & -1.820 & -1.483 & -1.296 & -1.283 & -1.986 & -1.879 \\
\hline Hansen-Pvalue & 0.702 & 0.580 & 0.761 & 0.782 & 0.880 & 1.000 & 1.000 \\
\hline
\end{tabular}

Standard errors in parentheses

${ }^{*} p<0.10,{ }^{* *} p<0.05, * * * p<0.01$

Period Effects are entered in every columns

In all columns religious attitudes of the country of residence (treated as predeterminate) and attitudes

towards trust and sex of American immigrants (treated as exogenous) are used as additional instruments In all equations appropriately legged included variables are used as instruments.

gap, ben, serv_va, epr_w treated as endogenous, tax_wed, udens and epl as prederminate

For all variables only the shortest allowable lag is used as istrument. 
Table A.1: Summary Statistics

\begin{tabular}{lccc}
\hline \hline \multicolumn{1}{c}{ Variable } & Mean & Std. Dev. & $\mathbf{N}$ \\
\hline epr_w & 63.552 & 14.198 & 47 \\
epr_y & 49.984 & 11.497 & 47 \\
hours & 7.442 & 0.093 & 45 \\
l_epr_w & 56.158 & 16.255 & 47 \\
l_epr_y & 52.415 & 11.025 & 47 \\
l_hours & 7.485 & 0.099 & 39 \\
women_cn & -0.034 & 0.696 & 46 \\
women_jp & 0.764 & 0.113 & 33 \\
youth_i & 0.114 & 0.897 & 47 \\
holidays & -0.374 & 0.432 & 47 \\
god & 0.513 & 0.643 & 47 \\
trust & -1.088 & 0.351 & 47 \\
week & -1.785 & 0.794 & 47 \\
imm_fework & -0.096 & 0.31 & 44 \\
imm_premarsx & 0.249 & 0.3 & 44 \\
imm_trust & -1.346 & 0.298 & 44 \\
ben & 30.64 & 13.833 & 47 \\
tax_wedge & 44.038 & 9.336 & 47 \\
epl & 2.217 & 1.124 & 47 \\
udens & 40.375 & 22.194 & 47 \\
gap & -0.621 & 2.196 & 47 \\
serv_va & 65.231 & 5.446 & 47 \\
edu_w & 8.499 & 1.861 & 47 \\
children & 0.58 & 0.106 & 47 \\
edu_y & 0.1 & 0.364 & 47 \\
pop65 & 14.318 & 2.196 & 47 \\
prot & 0.532 & 0.504 & 47 \\
cath & 0.404 & 0.496 & 47 \\
other_rel & 0.064 & 0.247 & 47 \\
\hline
\end{tabular}

